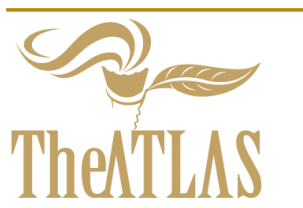

\title{
Deal with Complexity and Risk in Professional Relationship: The Transdisciplinary Logic
}

Luc Desbois, Françoise Kourilsky associé, Chargé d'étude à l'Ecole de Droit et Management de Paris Panthéon Sorbonne, Paris, France, Email: Id@francoise-kourilsky.com

doi: $10.22545 / 2012 / 00024$

\begin{abstract}
$f$ the individual is a black box, an encounter is a risk that has to be managed. In everyday life, no one stops to think about relationships. Unless they serve an intention that "is not self-evident", that makes an unusual emotion emerge. Do we think about the way we say hello to a colleague, unless we intend to get something from this "hello"? The transposition of the human relationship in the professional environment leads to a change in the reality level: putting on the clothes of a character and playing his part in a logical context that serves the aim and the plan of the organization, that itself is under the pressure of a demand that is quantitatively insatiable, and technically extremely demanding. Since the creation of wealth does not rely on an open-ended honey pot, de facto, the performance requirement becomes both an individual and group concern. The organization performance cannot suffer from the excessive variableness of the professional character's reactions. Paradox among the paradoxes, getting the best out of the relational potential of a system that is organized, focused, constrained, would then consist in establishing an evolutionary relational framework to control, without killing it, what, out of the professional environment, comes within what is uncontrollable and spontaneous. How then, can we deal with the complexity and the risk in relationship, leveraging the
\end{abstract}

transdisciplinary logic?

Keywords: complexity, transdisciplinary logic, human relationship.

\section{Dealing with Complexity and Risk in Relations}

\subsection{Ordinary Complexity and Risk in Relationship}

\section{Complexity, What Do You Mean?}

He who doesn't try to define complexity never meets it! Complexity is a fashionable buzzword, disturbing as well as convenient, often used inappropriately to refer to a problem as hard to work out as to solve.

In fact, complexity is radically distinct from simple, identity-related, defined, driven by norms, governed by the standard logic of single causality, linear, non-contradictory, anchored on a unique reality level.

Non-normative, illogical, evolutionary, rich and diverse, unstable, unspecified between the two poles of a contradiction, never reaching exclusively one or the other, ... tuned into at least two reality levels, complexity is indefinable ... at best complexity can be illustrated. The universe, the living, the human and his relationships, the thought, epitomize complexity: The individual is both - at 
the same time - this and that: open and impenetrable, adaptable and limited, contextual and identified,

self-sufficient and dependent, individualistic and systemic ... more or less according to situations.

\section{The Human is a "Black Box"}

More than any other complex "system", the human is a "black box" and nobody knows how the situation will be "digested" and what it will lead to.

Clever, sensitive, reactive, affective, emotional, relational, varying depending on context, the human is intrinsically variable. He looks at his life pursuing its course behind the scenes of his field of vision and through the narrow window of what he has learnt, as if he was producing the world without seeing himself acting and interacting in it? Deprived of his own image, of his external voiceprint, more or less conscious of the impact of his presence, of his contribution to the creation of reality, the human dreams of himself under all circumstances. The way he would liked to be looked at, the way he thinks he is expected, hoped, the way he sometimes idealizes himself, hoping that this will secure his most vital links. "Driven" by his emotions, the individual acts and reacts constantly to go beyond the initial antagonism between the mental and what moves it, at the same time tuned into his complexity, unable to master it, and into his wish to succeed in doing so. And sometimes he deludes and avoids himself, so that his is not disappointed by himself or to protect some of his illusions and utopias.

\section{An Encounter is a Risk That Has to be Managed}

If the individual is a black box, an encounter is another one! Relationships are vital for the dependent beings that we are, they are quasi-instinctive, since they are essential, natural and spontaneous. Rarely identified as an activity, even more rarely as a skill, the relationship is intimately linked to our person, at least to what our behaviors unveil about it, depending on contexts.

In everyday life, no one stops for a while to think about one's relationships. Barring a specific circumstance or difficulty, barring a notable change, unless one serves an intention that "is not self-evident", that makes an unusual emotion emerge. Do we think about the way we say hello to a colleague ev- ery morning? Unless we intend to get something from this "hello"? Then the relationship leaves its routine context to become strategic, and it obeys to another thinking logic. Whatever the issue then, the amazing thing is to see how the relationship activates the emotional potential of every individual, as if the encounter, in a very archaic manner, was activating basic fears.

Does the relationship carry the risk with such a load, and is the danger involved, whether real or symbolic, that vital? It is as if, being only through his relationships, the individual was symmetrically giving to them the power to annihilate him?

Indeed, the unknown can be destabilizing, and the unknown is the initial factor of an encounter. The variableness of the components of the context being infinite, the encounter between two individuals will always happen in a new context which will make of every new encounter "a first time", ... who would pretend that the weather has no influence on the mood of the protagonists?

Moreover, is there the slightest hope of control on the events beyond their statistical predictability and their approximate modeling? The immanence of the renewal of things, characterized by the illogical, the multifactorial, the unpredictable, the unstable, the discontinuous, the ephemeral ... does not allow sure transpositions, knowing that "other things can never be equal".

The unpredictability of an encounter is necessarily dramatized by the relational antagonism that prevails: will the interlocutors find a way to accept each other and let the dialog settle? The initial issue in every interaction lies in the consideration that they grant to each other from their own person, each one of them aiming at the confirmation of the self-image he or she wishes to "defend", and of the behavior that could flatter him or her in this situation. At a level at least compatible with the uncertain representation he has of himself in a referring circumstance.

Once the recognition step is over, the encounter comes straight to uncertainty, fate, risk, inherent to the confrontation of the sensitivities, visions of the world, points of view, convictions, of the characters and of the persons they shelter. The system made of the two present interlocutors has all the characteristics of a complex system, and of course it has its own emergent properties, (sensitivity, efficiency, equilibrium level, etc.) that appear only afterwards. The reciprocity involved, the inner regu- 


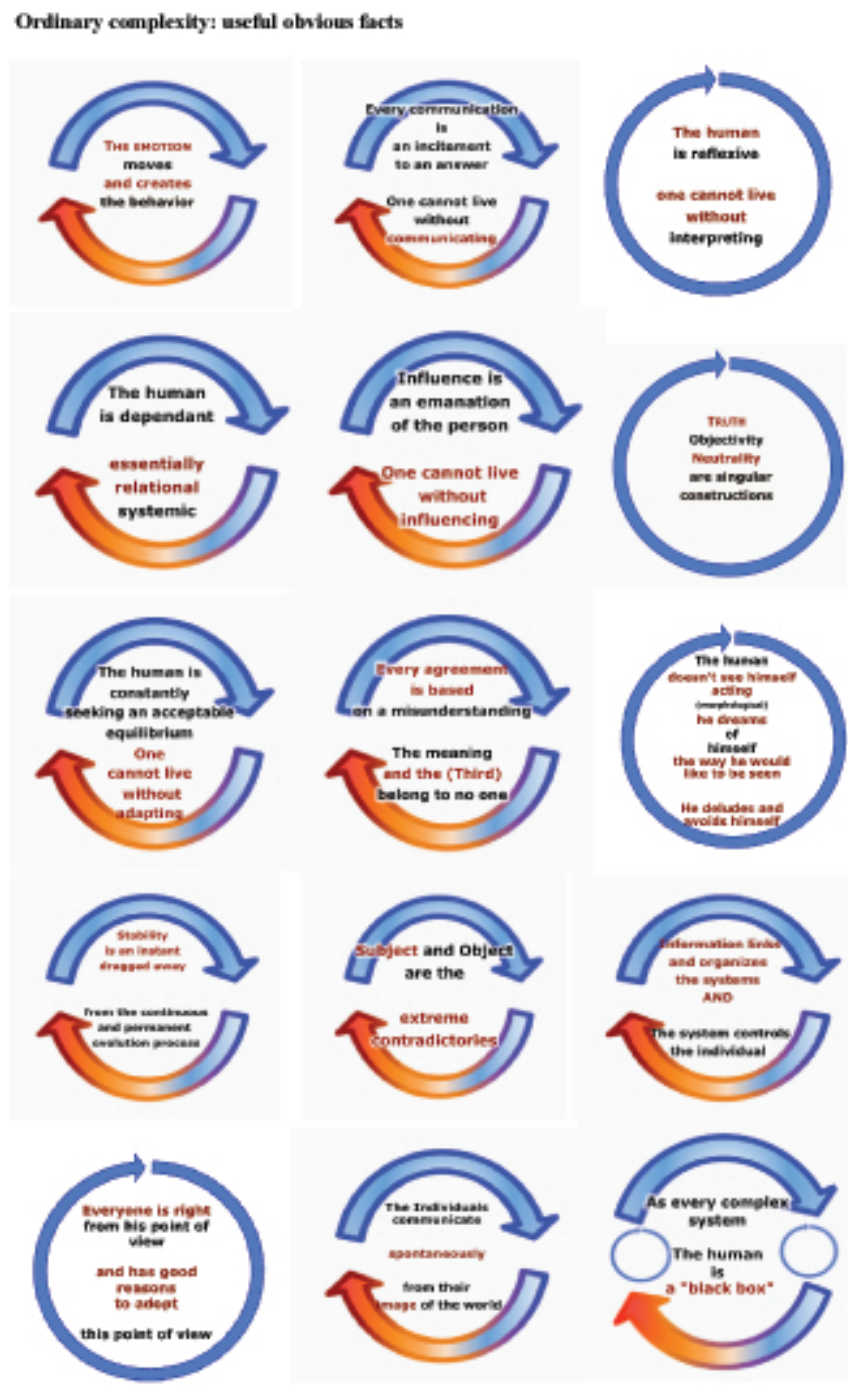


lation process of each one of the protagonists more or less consciously actualize their emotional state, their assessment of the situation, serve as a basis of their discernment that, consequently, induces their adaptation responses to the context. With this permanent double adjustment movement, a relationship has to be managed as a risk. Assumptions and bets, careful provocations, precautions, questioning and validations, appear in the interaction. Consequently, knitting the relationship presupposes the flexibility, the mobility in the relative positions, the agility that allows to go from one reality level to another in order to reconcile the points of view.

\section{Language is a Complexity Factor}

In an interaction, language (we should say languages) is a media that creates a gap between the observed tangible - what happens and what spreads out for each interlocutor - and what the communication renders.

The meaning of the words, the temporal interval, the memorizing of a frozen snapshot dragged away from the continuous and permanent actualization of the world, the person interpretation via their various characters and their contextual logics, the various reality levels that are used, determine the way things are worded, absurd and paradox being emerging figures of this.

Consequently, every agreement is based on a misunderstanding since anyone spends his life communicating from what is, in his view. From what the languages encrypt and distort, sometimes on purpose, in favor of a reassuring though sometimes unsatisfactory intersubjectivity.

\subsection{A Professional Organization is a Complex Relational System}

\section{The Professional Relationship Complexity}

A professional group is a key element of the economic and social system, central player of the adaptation of societies and place of integration. Workers, employees, executives, make up the "social fabric". This grouping of individuals without any prior reciprocal affinity predispositions, finds its raison d'être through the individual necessity to earn one's living, under the pretext of a collective aim that promises wealth.

The transposition of the human relationship in the professional environment leads to a change in the reality level. The professional relationship complexity covers new issues for the person: putting on the clothes of a character and play his part in a logical context that serves the aim and the plan of the organization. In particular, in certain contexts, adopting "unassumable" positions in a private situation.

\section{The Professional System Puts Some Pressure on the Relationships between the Individuals}

Every professional system controls the interactions between its elements, on various levels simultaneously. After a frenzied contractualization, the entity synchronizes its piloting system and the evolution of its countless reference frameworks to which its activity relates: national or international framework, economical framework, intellectual framework, scientific and technical framework, social framework, political framework, legal and regulatory framework, financial framework, etc.

The collaboration between an employee and their employer is defined by the employment contract: whether a date of "natural" ending exists or not, the presentation of the mission and of the actions to be undertaken, the notification of the relationship of subordination, of the rules of discipline ... Playing the game, the employee must take on objectives, submit to the assessment of their contribution, put their spontaneity and free will between the parentheses of their action. In this lies a major and permanent complexity factor of the relationship between the organization and the employee: how to deal with the last identity references of the individual - his emotional potential, his difference, the urge to establishing himself as a thinking personality having the power of controlling that personality - and the necessity to get a positive collaboration from the person?

How everyone will find a mean of establishing with their peers relationships that are constructive enough to meet the aim of the organization, the ambitions of its founders, creators, investors. Granted with the prerogatives, the insignia and the attributes of his office, will they go as far as to embrace the designs of the organization, thus finding again what they abandoned of their power and freedom when they signed their employment contract?

From these relationship modalities, basically depend the performance of the group, the quality of its products and of its results. 


\section{The Professional Relationship in the Shadow of Tabus}

The relationship remains taboo in the professional sphere, for the same good and bad reasons as in the personal life. Enough to be overshadowed or often brought up "indirectly", as a potential issue that has to be kept secret so as to avoid hindering the achievement of the collective plan.

Not being a calibrated, defined, standard and interchangeable supply that can be shaped, the relationship IS FRIGHTENING: potentially carrying some form of judgment, blame, criticism, divergences, seat and vector of the emotions that the professional character would like to master or to deny, since the "moods" in a professional environment can be damaging, even more so than getting angry ... or not assuming enough a distinct identity.

The relationship remains a synonym of out of place affectivity, femininity-related, and feared because of its potential dangerousness in case of demonstrated intrusion. Moreover, noteworthy is the fact that the words " influence", "relational strategy", "opportunisms" are most commonly linked to a negative intention, or to a strategy of ... inhumanly efficiency.

Conversely, the relationship is sometimes experienced as fascinating and very intellectualized: seeing through the interlocutor is the ultimate power of those experts "who know", and the insignia of recognition of "the initiated". "Position", "pathos", "affect", "search for meaning", the medical vocabulary of the deterministic pathologic labeling is often used by the "informed" manager.

\subsection{Augmented Man, Increased Complexity?}

\section{Augmented Man}

The end of the world's bipartition has brought us back to its wholeness et to the explosion of the demand for comfort. Doing away with lots of limits, the incredible train of progress creates new boundaries. Contradictions and tensions move, giving rise to new bipolarities, seeds of the dynamics of the infinite renewal of things.

Speed, dematerialisation, digital technology, information technology, medias, planetary and satellite interconnection networks... The consumer expresses a demand that is quantitatively insatiable, and technically extremely qualitative.
The advent of a second world, virtual and interconnected, stands in the way of what is tangible, disrupting the relationship between the human and their environment, denying separation, transcending the body limits, challenging the questioning that was previously expressed about reality. Armed with usurped powers, the individual extend himself by fusion - confusion - of the biological and the technology, of his own intelligence and of an added artificial intelligence, relegating any "corporal consistency" of himself in favor of the image that he projects on the screen of life. Where is the beginning and the end of what exists? The faster we go, the less time we have, and how can we gain even more time? Deemed time-consuming, complicated, old-fashioned, the human relationship is sometimes treated on the same level as the dematerialized information transmission, in the name of convenience, speed, and a cold "efficiency". When will quantum computers, teleportation, appear?

\section{Increased Complexity?}

The objects from daily life, co-authors of ordinary life, trivialize the feats of technology, as much by their functional accessibility as by their more than advanced home features. More and more integrated by medical intervention, the embedded technology leads the user to assume spontaneously the capabilities, promoting the value of an extra extraordinary that must be constantly reassessed, participating in the imaginary extension of the persons and in the inflation of the characters that they play.

How can the "augmented man" resist to the pressure et to the magnetic power of progress that haul him up to performance level which remained unreachable until now, validating the illusions and the utopias of omnipotence, that lead to the negation of obstacles, effort, and frustration? Consequently, how the individual could abandon the idea of maximizing simultaneously the yield of his various social positions, sometimes antinomic, with no concessions to the uncertainties of complexity, to the interdependence, to the risk, to the reciprocity of the commitments, henceforth too "burdensome".

\subsection{The Professional Organization Faced with the Demand of "Augmentation" of the Customer}




\section{The Customer's Law}

It is impossible for a professional organization not to meet the requirements of the customer, its growth driver above all, its employee also.

The periods when a balance exists between supply and demand are shorter and shorter, if any. The way the customer anticipates plunge the enterprise in an uncontrollable racing to feat. "Once and for all" is an expression that has disappeared. Failing to anticipate the advances in science, what professional group can content itself with being a "follower", or with playing minor parts?

\section{The "Economic Intelligence" is Relational}

Innovation, urgency, fund raising, return on investment are the key words of the economical and globalized piloting. In turn, to face these challenges, the "professional organization" can only behave as a tyrannical user, greedy for the resources that give it the power of creation.

At this stage in our evolution, the human resource might be more than ever the key to performance. Any marginal progress mobilizes transdisciplinary and transcultural skills, that only a "smart" cooperation can combine, arrange, juxtapose in the service of the objective. Solutions appear due to the confrontation of the specialties, skills and capabilities, the relational ability fostering the strategy to which the flexibility, agility and mobility contribute. A collection of great minds not having a good manner with people is outdated. Operating with a "relational economy" do not bear fruit anymore. The "economic intelligence" is transcended by doubt and relationship. Change cannot be considered as a transient temporary state anymore. Adaptation, change, renewal, those terms eventually join to form one body with the operating cycle of the professional organizations, this cycle being itself fully conditioned by the market demand. Of course, the managerial practice is all the more claiming all the attention since the renewal cycle is short. Change requires a close presence, both regulating, supporting, and also, with a special responsibility. A manager solicits his teams like a project driver does: in an ultra-constrained framework in terms of resources, timeframe, risks and quality. He's got to deal with the global complexity, in a context of the world competition, embracing vast and deep technical fields, he's got to take on the daily whirl, relying on "re- sponsible", "useful", "efficient" relationships.

Thus, the professional system must be open, in a waking state, able to capitalize on the dynamics of antagonisms at every level to feed its mobility and its adaptability. Likewise it must me able to rely on a "conductive" internal relational fabric, taken over by efficient infrastructures, fed by an ordinary creativity and by the opportunist collaboration of all its components, in relation with the potential of the context. The quiet, efficient creativity, lodges itself between persons, in the solidarity to which constraints, obstacles and difficulties give birth. In the reciprocity also, in the open-mindedness that encourages the expression of doubt, the exposition, the basic risk taking, the doubt that leads to confrontation through a learning approach based on experimentation and adjustment.

\subsection{Piloting the Professional RelationshiP}

Since the creation of wealth is not a matter of transcendence, and does not rely on an open-ended honey pot, consequently the performance requirement that is placed on the shoulders of the managers becomes both an indvidual and group concern, for a primary and simple reason that should be kept in mind: the distributed wages are debited from the wealth that is collectively created. Consequently, a professional group cannot rely on the uncertainties of the interpersonal affinities to succeed, its objective not being to change it into a vacation club but rather to encourage the establishment of Responsible, Useful, Efficient relationships.

\section{Minimizing the Variableness in the Relational Performance}

The organization performance cannot suffer from the excessive variableness of the professional character's reactions, this character being himself under the confusing influence of his own person since in a close interaction with this person. Even if an employee under contract is bound by the constructive reciprocity of his contribution to the result. Eventually, the multiplicity of the interactional levels and the variableness of the associated behaviors, combined to the fate of the occurrence of events, could expose a professional entity to a near-untameability of the relationships among its elements, and consequently to a global loss of efficiency. 
Both creation and achievement need a relational base that is predictable enough to ensure the right level of confidence allowing for the risk taking and the fertile cooperation. A professional team does not get the same results when it is leaded by a manager or by another one, a manager's action does not produce the same efficiency with a team and with another one, in an organization or in another one. With the same resources and the same manager, in another context, a team will not achieve the same results. The multifactorial variableness of the output is less and less acceptable, even less that it must be approved by the finance.

Paradox among the paradoxes, getting the best out of the relational potential of a system that is organized, focused, constrained, would then consist in establishing an evolutionary relational framework to control what, out of the professional environment, comes within what is uncontrollable and spontaneous. Indeed, an additional reference framework, but also a space into which the characteristics of the individual and global relational efficiency could fluctuate with no impact on the result quality. Accurately and firmly controlled, the individual creativity can then express itself through a personal interpretation of the office, while preserving the necessary leeway ensuring the minimal fulfillment of the individual.

\section{A permanent Reading of Contributions}

Getting the Relationship out from its Obscurity

Exposing the relationship as a capability, an activity, a skill that is perfectible, both related to identity and strategy, opens the doors of new possibilities for anyone. Consequently less experienced as a deterministic factor than valued as the central potential of success, the relationship can be considered as an individual and collective development project, out of the judging or frightening framework of the moral if not pathological labelling

When this happens, the irrational nature of the relationship can be softened if its ternary dynamics and the energetic emotional load that can be exploited, are put into light. But this does not mean that the relational risk has been swept away, on the contrary. It can be managed in a responsible way like any other risk, especially as the source of an antagonism between the best and worst, that, according to the occurrences and the context, can emerge under its conciliatory form.
Such an exposition of the Responsible Useful and Efficient relationship would allow a kind of control, and would make anyone accountable for the piloting of their activity. The objective being to put into light the creation potential of the exchange, to get the best of it in a very pragmatic way by dealing with all the aspects of its complexity.

\section{A Process}

To achieve this, eventually, one should establish a reference process that would focus on the permanent regulation of the "professional relationship efficiency", identified as strategic before any other, carrying the characteristics of the relationship into the limits of a variableness that is appropriate to the organization's requirement in terms of results. Even though the management processes are the least formalized, no doubt that placing officially and explicitly the relationship efficiency at the highest ranking of the key processes of an organization, means a lot. From an incentive and strategic perspective, it would even be wise to outline its objectives and to make of it a criterion for appraising the individual performance.

Concomitantly, the exposition of individual and collective development objectives, would draw in the landscape of the system the conception of an ever possible improvement of the cooperation.

Aiming at a Responsible Useful and Efficient relationship, means establishing a structural characteristic that extends to the whole system, all levels and all stages of the completion of the product or delivery being taken into account. Establishing efficiency as the main thrust, as being an integral part of the social contract of the organization, can only lead to a spirit and to behaviors that foster in the long term the adaptability of the system and of its aim.

\section{A Transdisciplinary Logic to Deal with Complexity and Risk in Relationship}

Nowadays, the words objective, result, speed, and profitability, structure the way a manager expresses himself. How to answer these injunctions when dealing with the human relationship, its dilution and its mediatization, its contradictions, its emotional and affective components, the urgent constraint for 


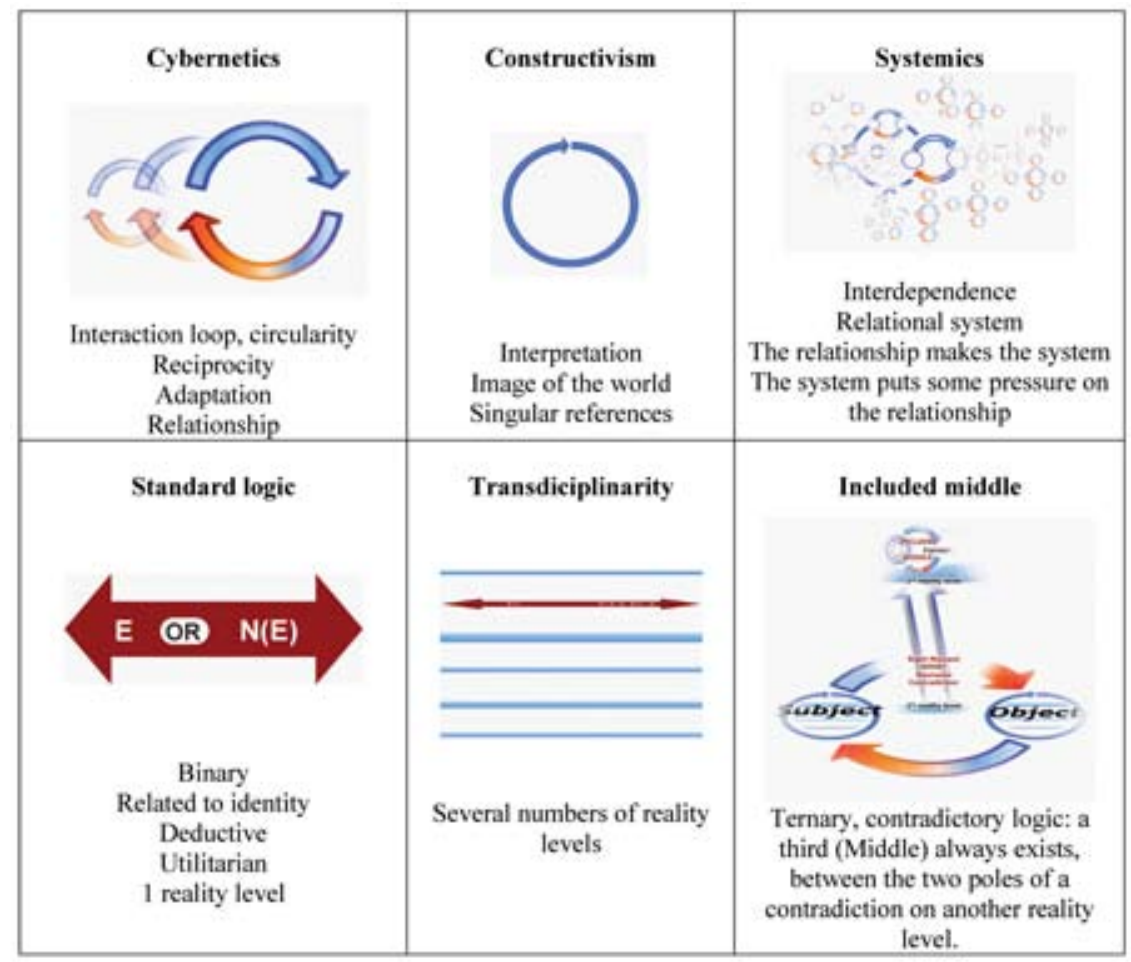

Figure 1: The logic of the included middle is transdisciplinary.

adaptation and change, the necessity to reconcile multidisciplinary and multicultural points of view...?

\subsection{Elements of Logic}

\section{The Logic of the Included Middle is Transdisciplinary}

Complexity has its own logic. Dynamic and pragmatic, it focuses on the interactions as a determinant of any system, of its characteristics and of the results it achieves. Applied to piloting the relationship, especially in a professional context, the logic of complexity allows to avoid the traps in communication, to deal with constraints, and to go beyond lots of resistances and relational problems. It allows to go from what is potential to what is actual. The logic of the included middle is ternary, transdisciplinary (see Figure 1). It includes the standard logic, uses the properties of systems, leverages the adaptation and regulation dynamics of cybernetics, deals with non-normativity, contradiction, paradox, or ambiguity.

The logic of complexity, also called logic of the included middle is the logic of conciliation. Il is especially efficient to allow the change of individuals and groups. The aim of the following is to highlight the inner workings of the logic of the included middle in order to suggest some relational piloting tools that are easy to implement, and efficient in "almost all" situations.

- The logic of the included middle allows to get out of the destructive relationship between the 2 poles of a contradiction, through the simultaneous existence, at another reality level, of a singular Third (middle) within which the opposites coexist, without merging and without totally excluding one another ${ }^{1}$ (see Figure 2).

- A reality level is "a set of systems invariant under the action of a number of general laws". From a reality level to another, "there is a breaking of the laws and a breaking of the fundamental concepts"2.

For instance, in the professional relationship area:

- valuing the doubt as a resource / wanting to be right despite all opposition;

\footnotetext{
${ }^{1}$ Bulletin Interactif du Centre International de Recherches et Études transdisciplinaires no: 14 - Avril 1999.

2 "Qu'est-ce que la réalité" Basarab Nicolescu, Editions Liber, 2009.
} 


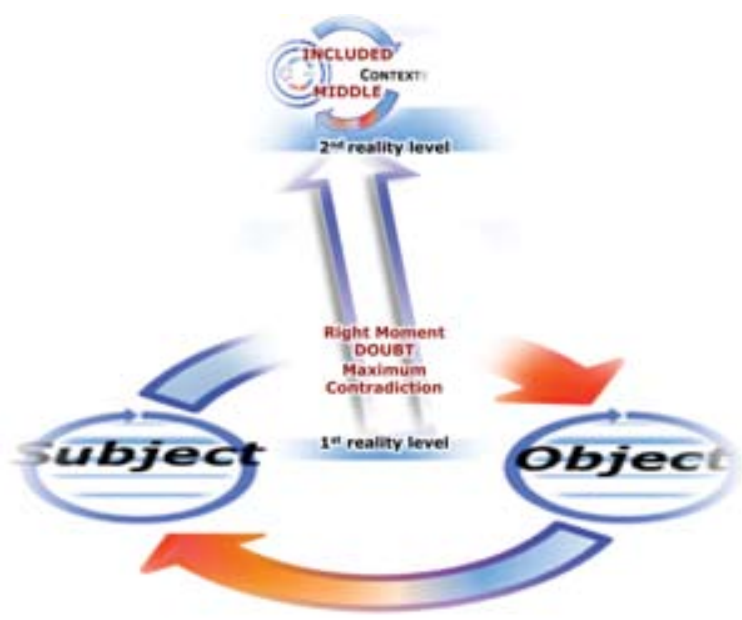

Figure 2: The logic of the included middle, is the logic of the conciliatory option.

- dealing with the vagueness, the uncertainty and the unpredictable / acting only when there is no doubt;

- trying to be useful and efficient / seeking objectivity, neutrality, truth;

- choosing one's responsibility / being subject and executing;

- using gaps as a support for constant adaptation / pointing mistakes and sanctioning them;

- being future- and solution-oriented / seeking the causes ...

The logic of the included middle is ternary and dynamic, iterative; it considers at least two reality levels (see Figure 3).

- On one reality level, the 2 poles of a contradiction obey to the antagonism principle: the actualization - A - of one of the poles drives simultaneously the potentialization -P- (repression, latency) of the other, which never disappears.

- The 3rd pole emerges from the reciprocal relativization of the 2 others, among all the intermediate degrees of the actualization/potentialization, to a perfect, rigorous equilibrium, at which the two opposed actualizations cancel each other out. Maximum antagonism point between the two opposites, the 3rd pole is consequently the place where the doubt lies, the right moment, the dynamic basis from where, at the same time and on a second reality level, simultaneously emerges the Included Middle that brings together les opposites without merging them. (Cf Basarab Nicolescu)

$$
\mathbf{A}(E) \text { OR } \mathbf{P}(N o t E) \Rightarrow T=(E) \underline{\text { AND }}(N o t E)
$$

\subsubsection{The Logic of Complexity Includes the Standard Logic}

- The standard logic is analytical, deductive, utilitarian, efficient to understand the mechanical progression of the sequences, the breakdowns ...

- Single causality logic, the standard logic is binary, linear and related to identity, it considers a unique reality level. Also called logic of the Excluded Middle, it is based on the premise of non-contradiction, which excludes the simultaneous existence of the two contradictory aspects of one element. Unless it creates a paradox or an absurdity whose only way out could be the reciprocal destruction of the two struggling poles of the contradiction.

It excludes the existence of a middle between two contradictory terms.

\subsubsection{The Logic of Complexity Leverages the Systems Theory}

- The human is relational, systemic. 


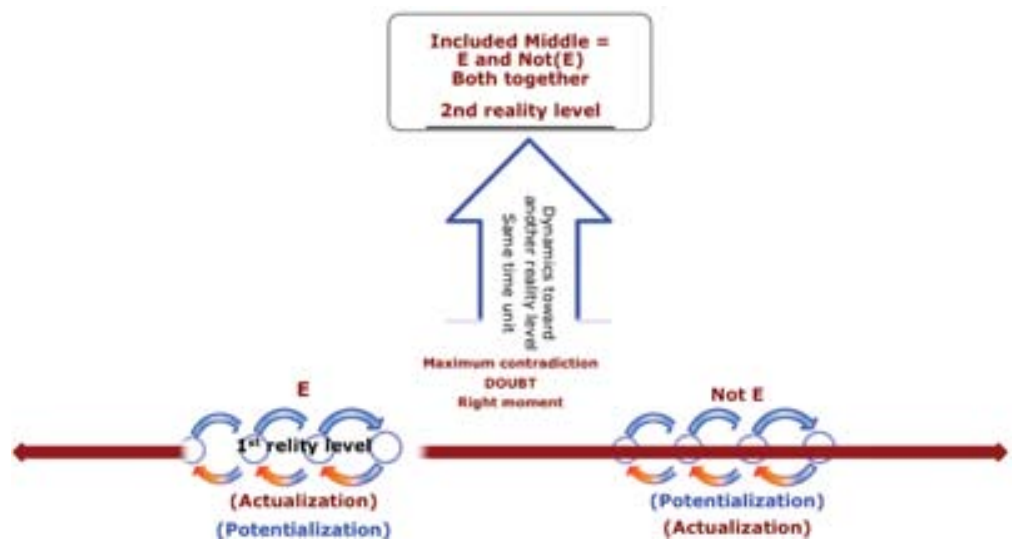

Figure 3: The "3D" r elation.

- The individual related to his environment constitutes an open system, that is organized, selfregulated, basic.

- The relationship is omnidirectional and multifaceted (multicausality and equifinality).

- Every individual is an element from many systems at the same time.

- The relationship makes the system on a second reality level, with characteristics and singular achievement capacities which differ from those of its various components on the first level (see Figure 4).

- Reciprocally, the system controls the individuals to maintain an acceptable equilibrium, given its own constraints.

- Every system is a system of systems.

- The interdependence produces the butterfly effect.

\subsubsection{The Logic of Complexity Leverages the Dynamic, Iterative Principle of Cybernetics}

- Information makes relationship.

- One cannot live without communicating. In itself, presence is communication.

- One cannot live without adapting.

- One cannot live without influencing.

- Information and reciprocal adaptation answer, follow different thought progressions and make up the interaction loop.

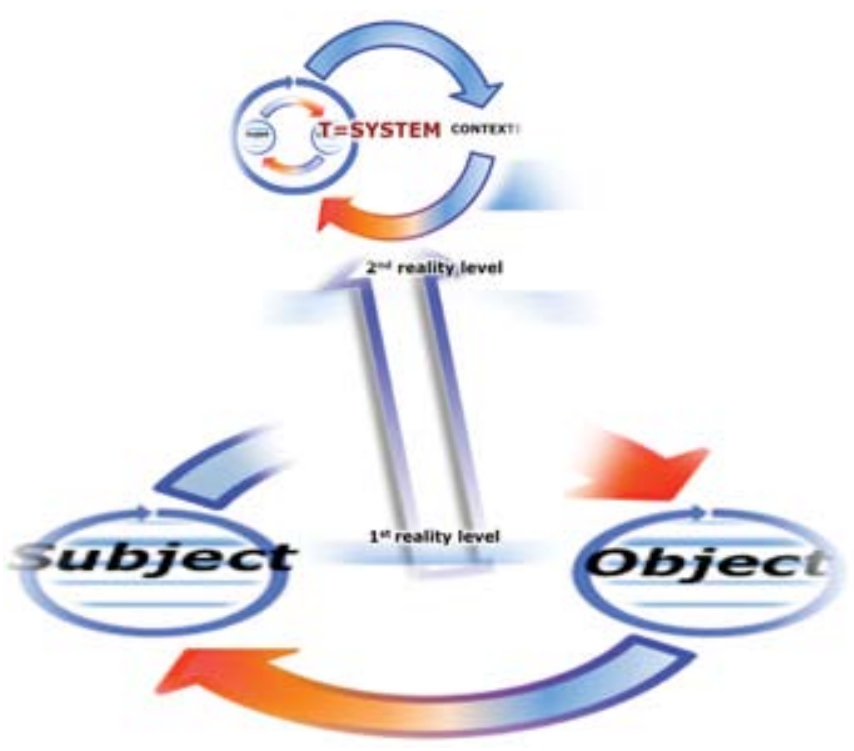

Figure 4: Elements in relationship make a complex system on a second realtity levell. 


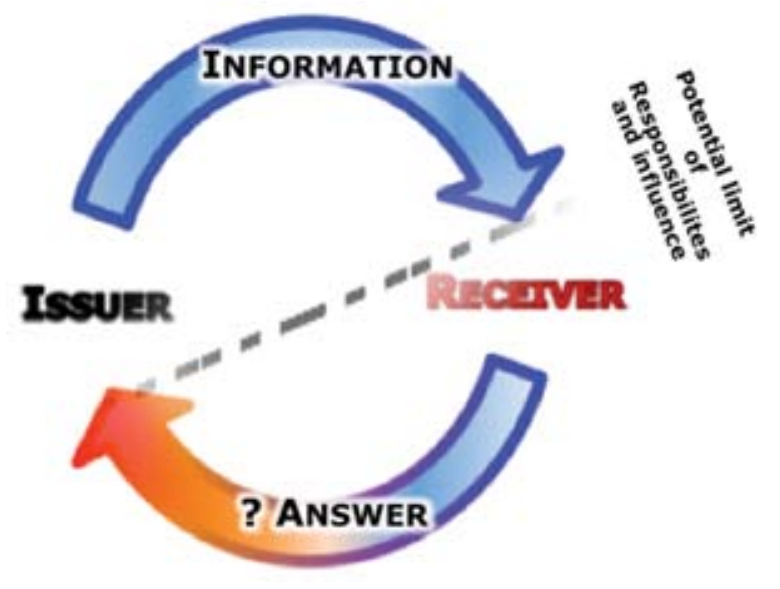

Figure 5: Reciprocity, interdependence in interaction loop.

- In an interaction, at best the issuer controls the information they send to their interlocutor.

- Reciprocity structures the interactional face to face: no one can evade his/her responsibility (see Figure 5).

- The relationship is built through the sequence of interactions, from regulation to adaptation, from one change to another (see Figure 6).

\subsubsection{The Logic of Complexity Deals with Non-normativity}

- One cannot live without interpreting.

- Truth, objectivity and neutrality are subjective constructions, without normative opposable value.

- Subjectivity echoes non-normativity.

- There is no absolute normative reference, opposable whatever the context.

- The reflexive skill refers to reflection, imagination and self-concern (see Figure 7).

- The human doesn't see himself acting, he has no conscience of the mark he leaves, he dreams of himself the way he would like to be seen, he deludes and avoids himself

- The "intellectual" area is the one of all possibilities, of theory, abstraction, imagination ... as well as of rationality, will, and control.

- The world of reflexivity goes round in circles, in a tendency to be self-sufficient.

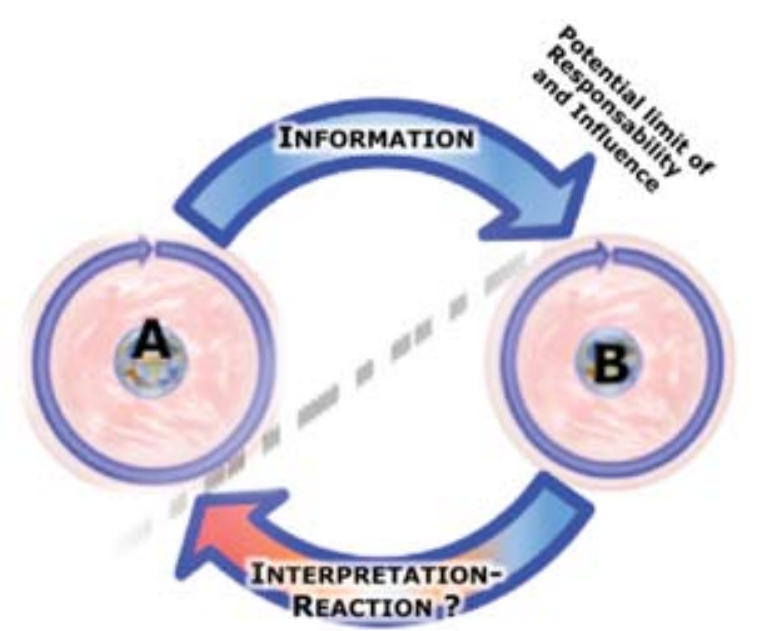

Figure 9: The reflexive loop and the interactional loop feed themselves reciprocally.

- Language mediates, encrypts, creates a gap between the tangible and the rendering of it (see Figure 8).

- The individuals communicate reciprocally from their interpretation of the world (see Figure 9).

\subsection{References and Supports in Piloting the Professional Relationship}

\subsubsection{Three Piloting References}

\subsubsection{Sample Founding Changes in the Reality Level $\Rightarrow$}

- shaping the strategic relationship / relying on the uncertainties of the contextual variations;

- making complementary what is contradictory / fighting against, conflicting, creating dilemmas;

- valuing the doubt as a resource / wanting to be right despite all opposition;

- dealing with the vagueness, the uncertainty and the unpredictable / acting only when there is no doubt;

- trying to be useful and efficient / seeking objectivity, neutrality, truth;

- choosing one's responsibility / being subject and executing;

- using gaps as a support for constant adaptation / pointing mistakes and sanctioning them; 


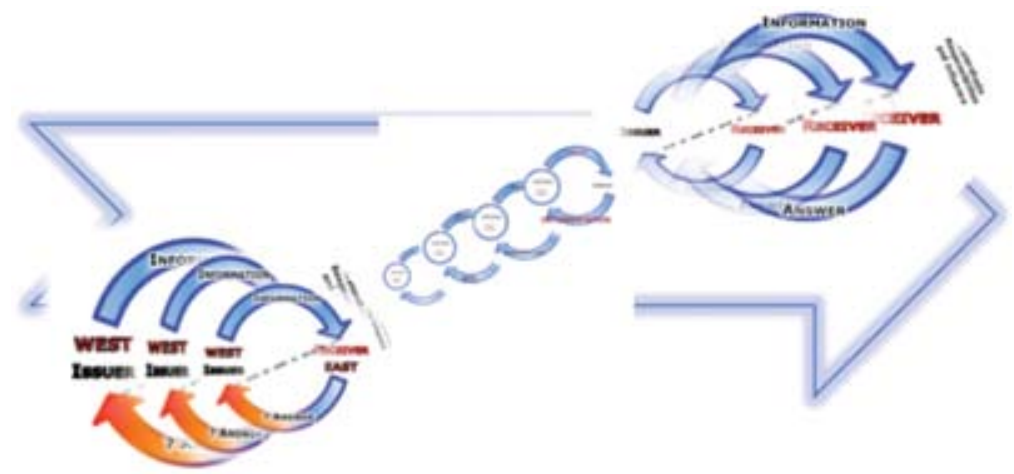

Figure 6: continuous adaptation, and change from one realty level to another.
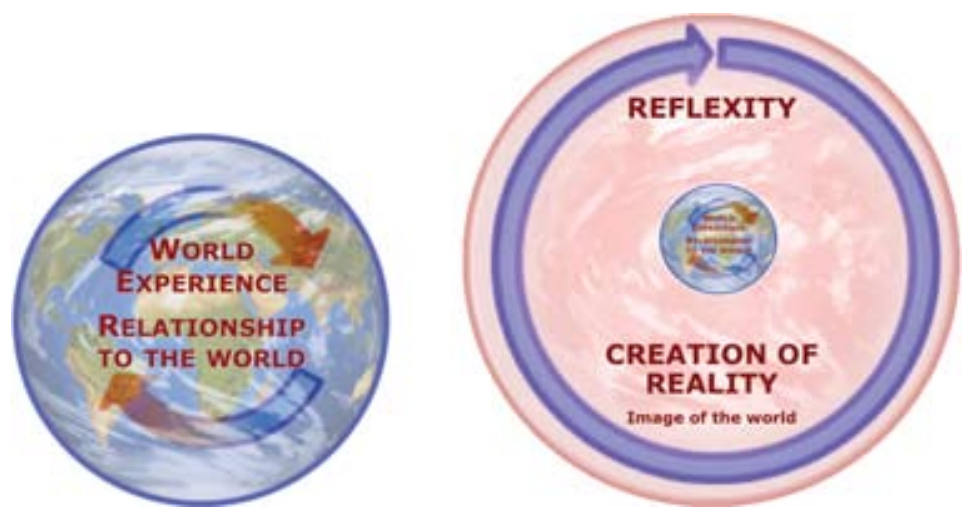

Figure 7: From world experience to the internal reflexive image of the world.

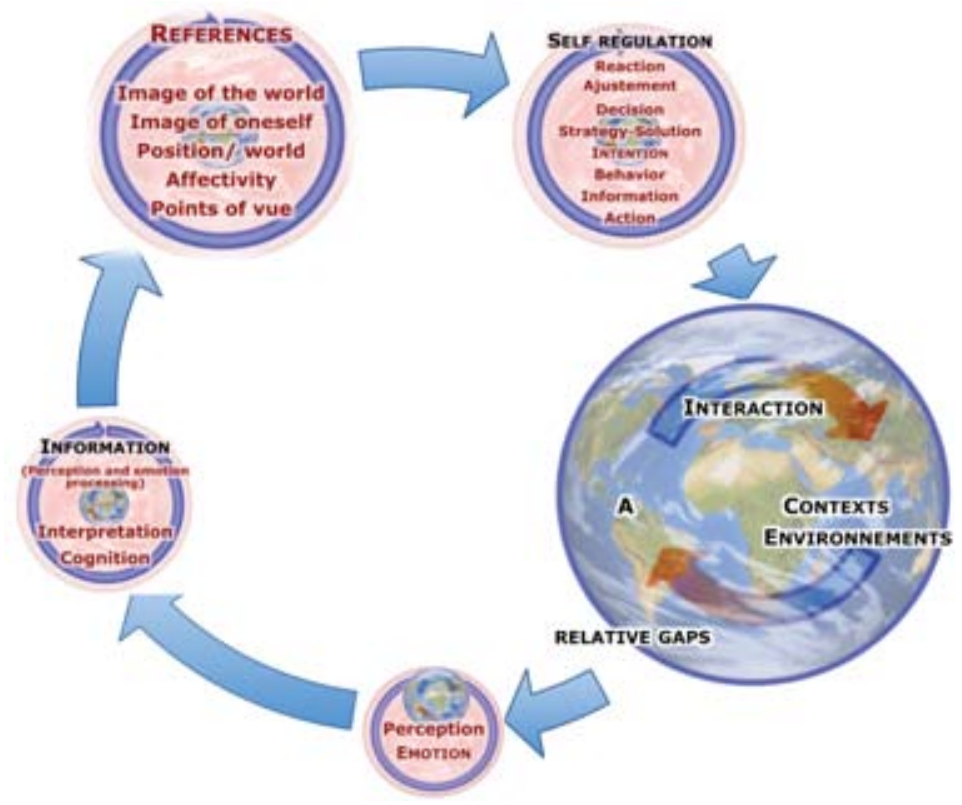

Figure 8: Reflexive process of creating the image of the world and behavior.

- being future- and solution-oriented / seeking the causes;
- aiming at minimal relevant objectives / aiming at excellence at all costs; 
- adopting the efficient relational strategy / doing psychology;

- combining reflection and action / becoming aware without taking action;

- replaying an unsatisfactory interaction / what is done is done.

\subsubsection{Aiming at a Responsible Useful and Efficient Relationship $\Rightarrow$}

- practicing pragmatic empathy, inducing useful and efficient reciprocity;

- focusing on the interlocutor, seeking his/her logic, aligning his/her answers in order to pilot the dialog;

- agreeing on action references that are explicit and relevant in the context, aiming at minimal objectives;

- putting relational strategy in the service of the result, using the potential of the context;

- looking after one's communication: mix of languages, perceptive and careful questioning, and inductive rephrasing and communication;

- practicing flexibility, mobility and relational agility: chosen and assumed responsibility, relative position, reality level;

- adopting the iterative dynamics of constant adaptation and regulation;

- combining reflection and action.

\subsubsection{Inducing and Driving Change $\Rightarrow$}

- ensuring that all dispositions of precaution, experience and common sense have been implemented;

- the initial risk review is the founding act of every change;

- establishing a close, specific and identified support process;

- inductive relationship and communication lead to change: deconstructing, de-framing, reframing, provoking, calming down;

- when common sense doesn't go in the right sense, one

\subsubsection{Piloting Supports}

\subsubsection{Pragmatic Empathy}

- "Having a good manner with people" is a living skill that has to be practiced, fed and kept alive.

- The constructive reciprocity feeds on relationship:

- the presence, time and attention that one gives and displays (look, focus), are marks of consideration; "In a negotiation, the less you have to give, the more you have to receive!"

○ "offering" the expression space to the interlocutor.

- Creating a relationship between two people is an unknown, a new system whose characteristics and result arise from the face to face, and always subject to the variableness of the context:

o every encounter is a first time, a risk in itself, that has to be prepared and managed as such;

o the sensitive and reactive individual is a black box, he is unpredictable, changing, contradictory;

- an encounter is an emotional confrontation that opens with the reciprocal confirmation of the interlocutors;

- each interlocutor brings his/her own world, with which he/she is in an intimate, affective and identity relationship.

- Empathy contains the Responsible Useful and Efficient relationship, and deploys it at the same time:

- recognizing the interlocutor in the legitimacy of his vision of the world in order to open empathy to constructive reciprocity;

o establishing the interlocutor as an autoregulation barometer induces the relational agreement; an information efficiency reads in the answer; "What is not alike contrasts ... what contrasts prompts the other part reciprocally";

- making incentive "narrative rephrasings" using the logical references of the other avoids projection ("putting oneself in somebody's place", aiming at persuading, im- 
posing one's point of view, come down to conflicting);

- apprehending the potential as well as the limits of the other in the situation, so that the included middle emerges from the relationship and through the interlocutor (the included middle doesn't exist at first sight) $)^{1}$

$\circ$ assigning strategically the meaning of things to the other, using his differences, his need of contradictory assertion, to make the cooperation "ego logic", seeking complementarities, that promote emulation and co production (see Figure 10).

- From a spontaneous influence to a strategic, Responsible, Useful, Efficient influence:

- seeking the other's point of view in order to accompany him/her in the relationship towards the result;

- agreeing on an exclusive shared reference, determinant of the Useful and the Efficient, third mediator and catalyst in the relationship (see Figure 10);

o putting forward one's own share of responsibility, taking the initiative, gives some visibility, and allows to manage the context, if the relationship is packaged with the right communication;

- developing the appropriate adaptability to the variableness of situations and to the unpredictability of the behaviors that are met: agility from one reality level to another, flexibility and mobility regarding one's relative relational position;

○ using what is latent, highly potentialized and limiting in an interaction, leads to a change in the reality level;

o anchoring the relational strategy in the vision of the world of the interlocutor;

$\circ$ positioning oneself as a resource, opening the dialogue to the third, consists in escaping from the relational, emotional and affective field, in order to avoid any sterile a priori.

- converting DOUBT into a resource: every limiting thought or emotion can and must be used;

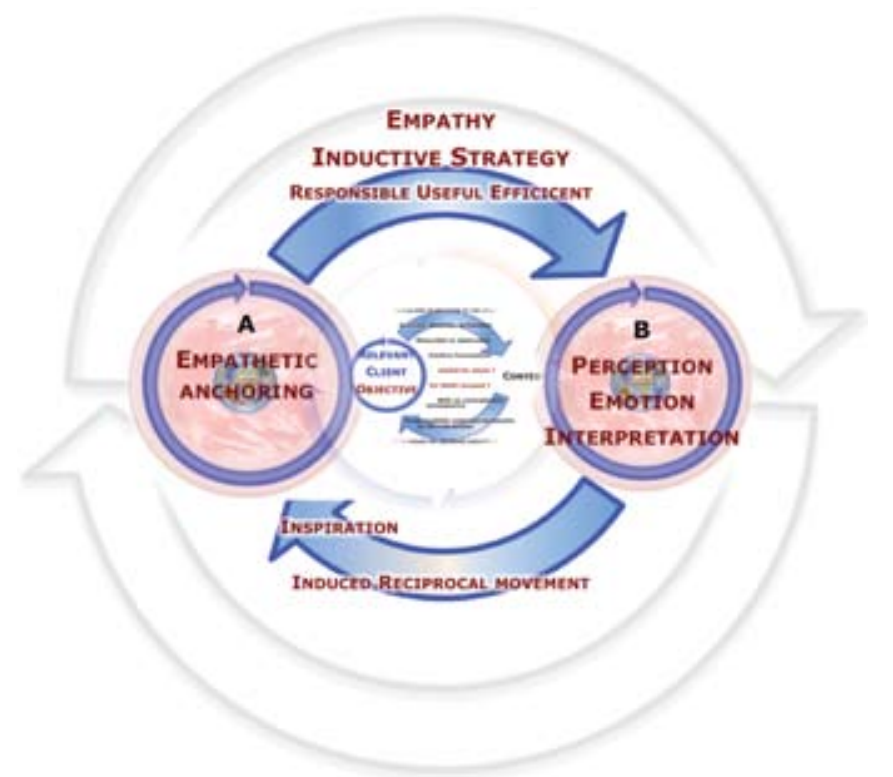

Figure 10: "Using" instead of "fighting against", knitting the co-realization with the relationship.

- one can always replay an interaction that doesn't seem satisfactory;

- capitalizing on the energy that emerges from the antagonisms at all levels: differences and gaps, related to chosen and validated references, are contextual information that prompts to movement;

o giving up trying to control what is uncontrollable, working with one's illusions and utopias.

\subsubsection{The Relevant Objective is Third, Regulator and Catalyst in the Relationship}

- Without any normative opposable value, and the constraint of the result required by the system, the useful and efficient relationship exists only in reference to a norm of action that is contextual, explicit, shared, relevant with regard to the constraints of the system (see Figure 11-12).

- Agreeing on the relevant objective is a founding step of every collaboration.

- The relevant objective is third, regulator and catalyst in the relationship, it allows for considering another reality level, and projects beyond the tricky relational situations (see Figure 13).

- The vision is a middle/long-term projection of 


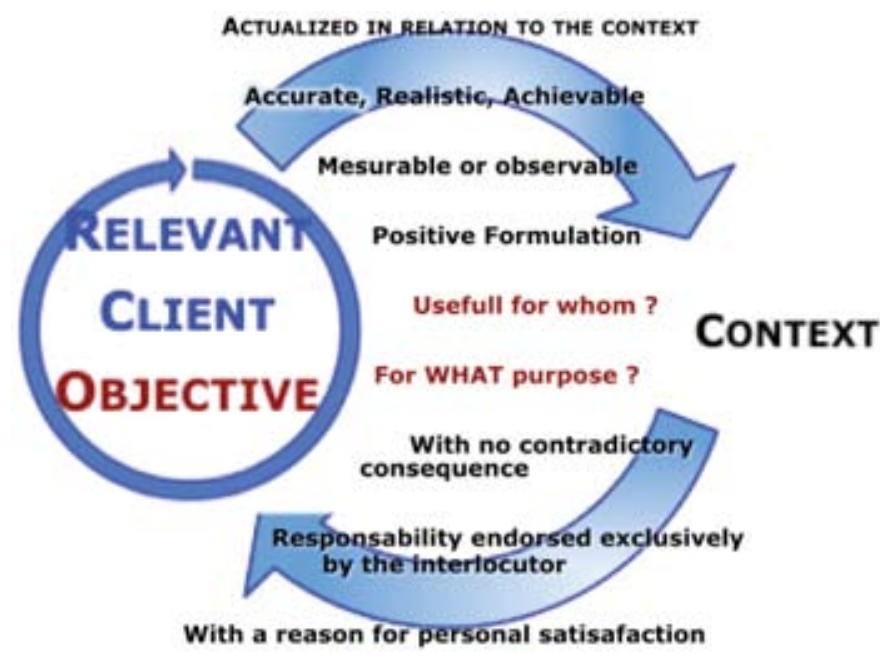

Figure 11: Criterias of the relevant objective.

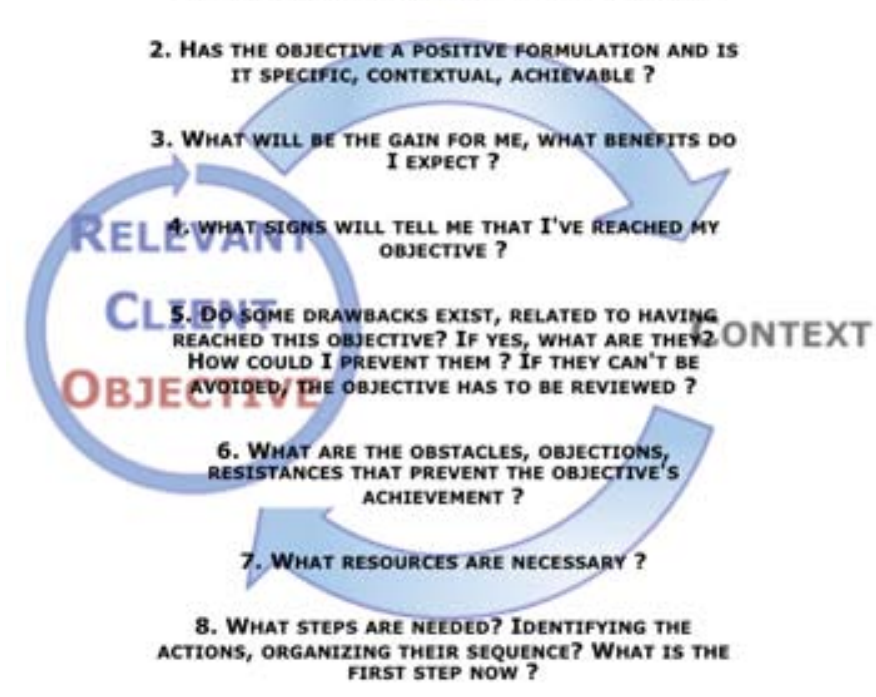

Figure 12: A question list to check the relevant objective.

the initiative and adaptation capacities of the organization in the service of its mission, of its object, of its end. It clarifies itself at a certain point through a project and through objectives that divide and split themselves (see Figure 14).

- Relevant objective, project are interactional references that actualize and adapt themselves:

o its definition and its realization are synchronized with the evolution of the context;

o the realization of the objective always serves a client, whoever he is (see Figure $15)$.

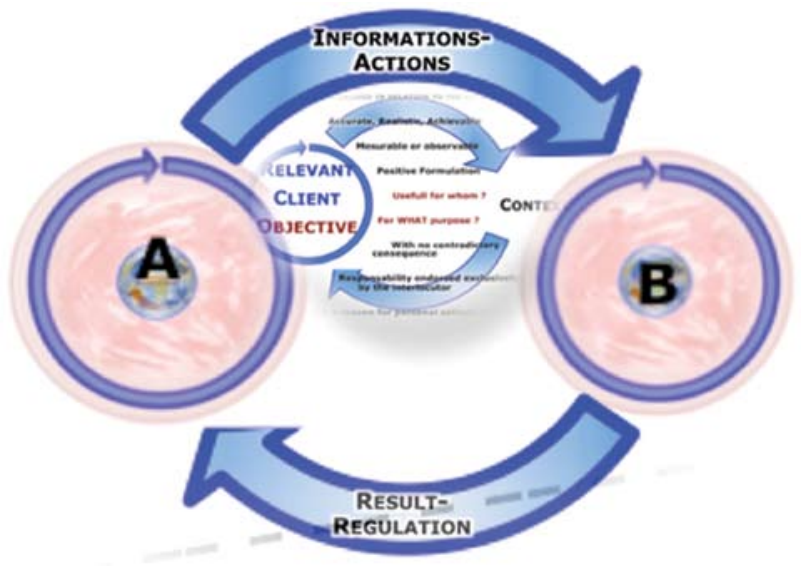

Figure 13: The relevant objective is third, regulator and catalyst.

- Process, project, objective are founding references at every step and at every level of any realization. The relational dynamics is central, between the individuals and between the functional sub-systems, for the sequencing and coordination of activities. This way, contributions and responsibilities are valued for autonomy and quality. Towards a matrix organization?

\subsubsection{The Choice of Responsibility: From Determinism to Relational Strategy}

- The circularity of communication and relationship, interaction loops sequence, lead to the superimposition of the interactional WEST-EAST poles that meet and mix up (see Figure 16).

- Every adaptation answer becomes an information that, in turn, gives rise to an adaptation answer, thus creating an endless renewal process;

- Every end is the beginning of something else, the expression of alternation and of constant renewal in the course of a process;

- Impermanence is the essence of continuity, of the living, of performance; Stability is an illusion, equilibrium is precarious, an instant between the end of something and the beginning of something else;

- The defined, the identified, is deprived of its qualities since they only exist through emergence, expansion;

- What is "apparent" is already in decline 
and in conflict with what is "new" and invents itself.

- The issuer becomes simultaneously the receiver and the receiver becomes simultaneously the issuer, like in any couple of opposites;

- Causes and consequences are superimposed, until they merge. The chicken or the egg! What is the use of seeking the "WHY of things" if all is contextual subjectivity?

- Every individual has the choice of placing the line that divides responsibilities and influence, at the level of what he accepts to take on in every interaction and in every professional role play (see Figure 17).

- The chosen and assumed responsibility-taking generates a useful and efficient influence.

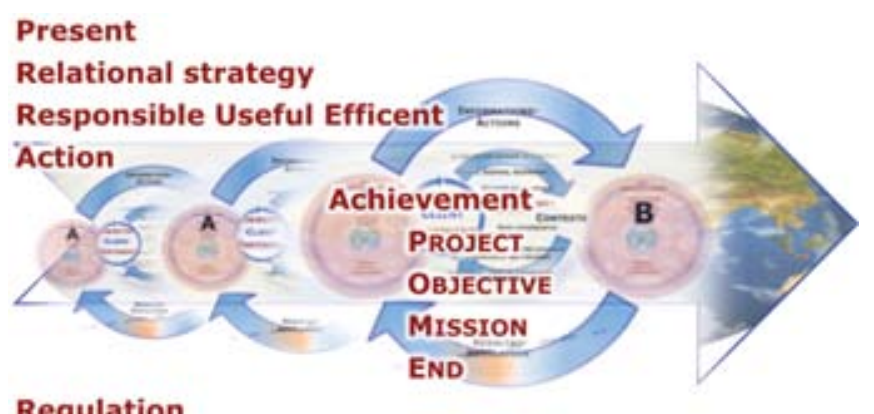

Regulation

Figure 18: A pragmatic attitude that invests the present in the realization and the strategic preparation.

It's the destination that leads to get on a train, not where it comes from! Preparing oneself to everything, even to what is unpredictable!

\subsubsection{Logic of Result: Solution-Orientated and Future-Orientated}

Situation potential:

- Tendencies

- Timely moment, included middle

- Influential individuals

- Context Resources
- The logic of result feeds on a pragmatic attitude that invests the present in the realization and the strategic preparation of the future in the direction of the project.

- Piloting the relationship comes under the "opportune opportunism", from the appropriate adaptability to the variableness of the contexts, of the human emotions.

- Cultivating an "opportune opportunism", the capacity of using the potential of contexts at the right moment.

- The relational usefulness and efficiency lie in the seeking of the new possibilities and of the new complementarities: the interlocutors can choose to adopt a tendency to renewal or to let the course of what happens supplant creativity (see Figure 18).

- Moving from the "Why?", the seeking of the causes, to the "What happens, and how" and "How to deal with?", the seeking of the solutions in action.
$\Rightarrow$ If it is sometimes useful to go through seeking the roots of a prob- lem to make it solvable, such a step is indissociable to implementing a so- lution.

- The dynamic of adaptation and permanent regulation in the service of progress.

- The gaps that are noticed all along the realization of the objective are precious resources and sources of progress, reciprocal incitements that have to be used to adapt the objective and the solutions.

- From the search for truth, to the choice of Responsibility, usefulness and efficiency in relation to a relevant third reference, initially shared. Since truth, objectivity and neutrality are subjective constructions.

- Acting as a thinking person and thinking as an acting person: Responsibility-StrategyAction. Through strategic action, experiencing the world, confrontation to the tangible, to the limits, skills/competencies are acquired, through what is physically, sensorially and emotionally experienced, through adaptation. Being 

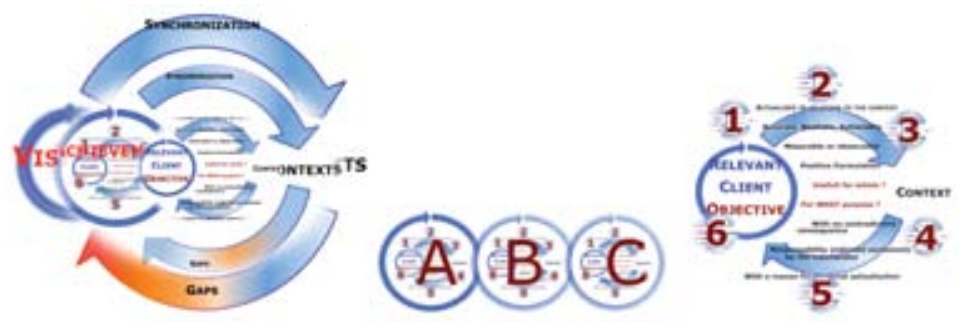

Figure 14: The vision clarifies itself through a project and objectives that divide and split themselves.

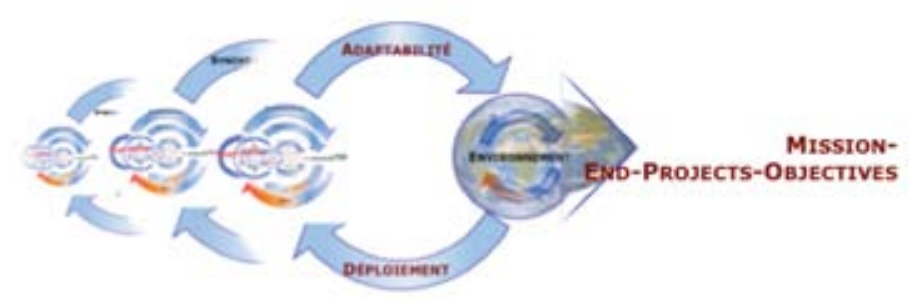

Figure 15: Relevant objective, project are interactional references.

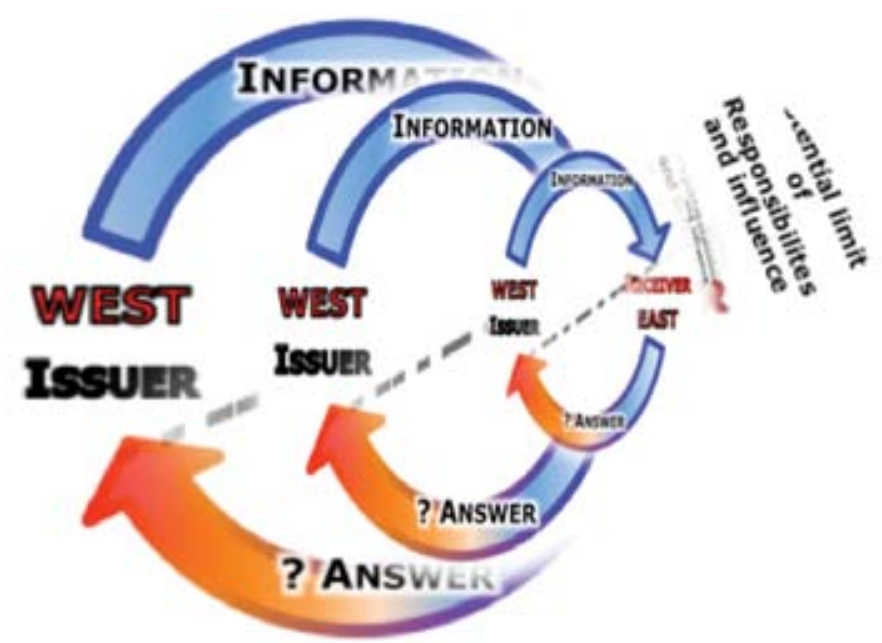

Figure 16: Superimposition of the interactional WEST-Issuer/EAST-Receiver. 


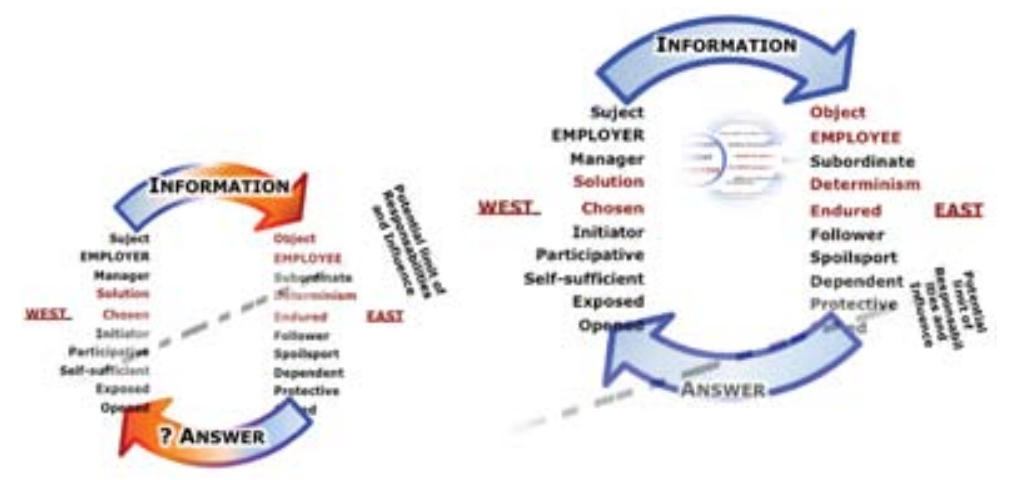

Figure 17: Moving the line that divides responsibilities and influence/ relevant objective.

aware of the problem is not enough to let the change happen.

\subsubsection{The Communication Packages and Opens the Relationship}

- Language is the first media.

- Communication is a paradox that creates paradox!

- A useful and efficient communication allows opening dialog, deconstructing the paradoxes in communication and making the included middle emerge: "The solution is beside the problem!"

* Pragmatic questioning and validations

- Gathering information with perspicacity and precaution:

- Pragmatic questioning combined to validations neutralizes any personal spontaneous crushing projection and is the universal key for any Responsible, Useful and Efficient cooperation;

- Faced with the contextual emotional load and affectivity, questioning is a bet ;

- Any ambiguity, impropriety in the interlocutor's languages, any paradox, must lead to dare asking one more question taking care of the form!

- Going beyond determinism: moving from the seeking of the causes, the "Why?", to the seeking of the solutions in action (see above), the "How to do?",

Since causes and consequences influence one another until they merge,
Since identical causes can lead to different results,

Since different causes can lead to identical results,

Since causes always are many,

Since observations vary according perspectives, everyone dividing the communication from his own point of view,

Since the present conditions the vision of the past ...

- Pragmatic questioning aims at getting descriptions to make the tangible emerge in a transubjective form, gaps instead of oppositions, working out the potential of the situation, identifying the influent persons, investigating the relational exchanges, the relative positions, the vision of the world - the position related to the context - and the interlocutors' associations (see Figure 19).

- Questioning and rephrasing are indissociable. Getting validations ("Yes" sets).

\section{* Inductive communication}

- The communication packages and serves relational strategy:

- the attention showed is an essential implicit language;

o the form of communication, the mix of the 4 direct languages, the utilization of the medias, the way they are chosen, are at least as incentive a the information itself, since they give some details about the intention aimed at in the relationship (see Figure 20). 

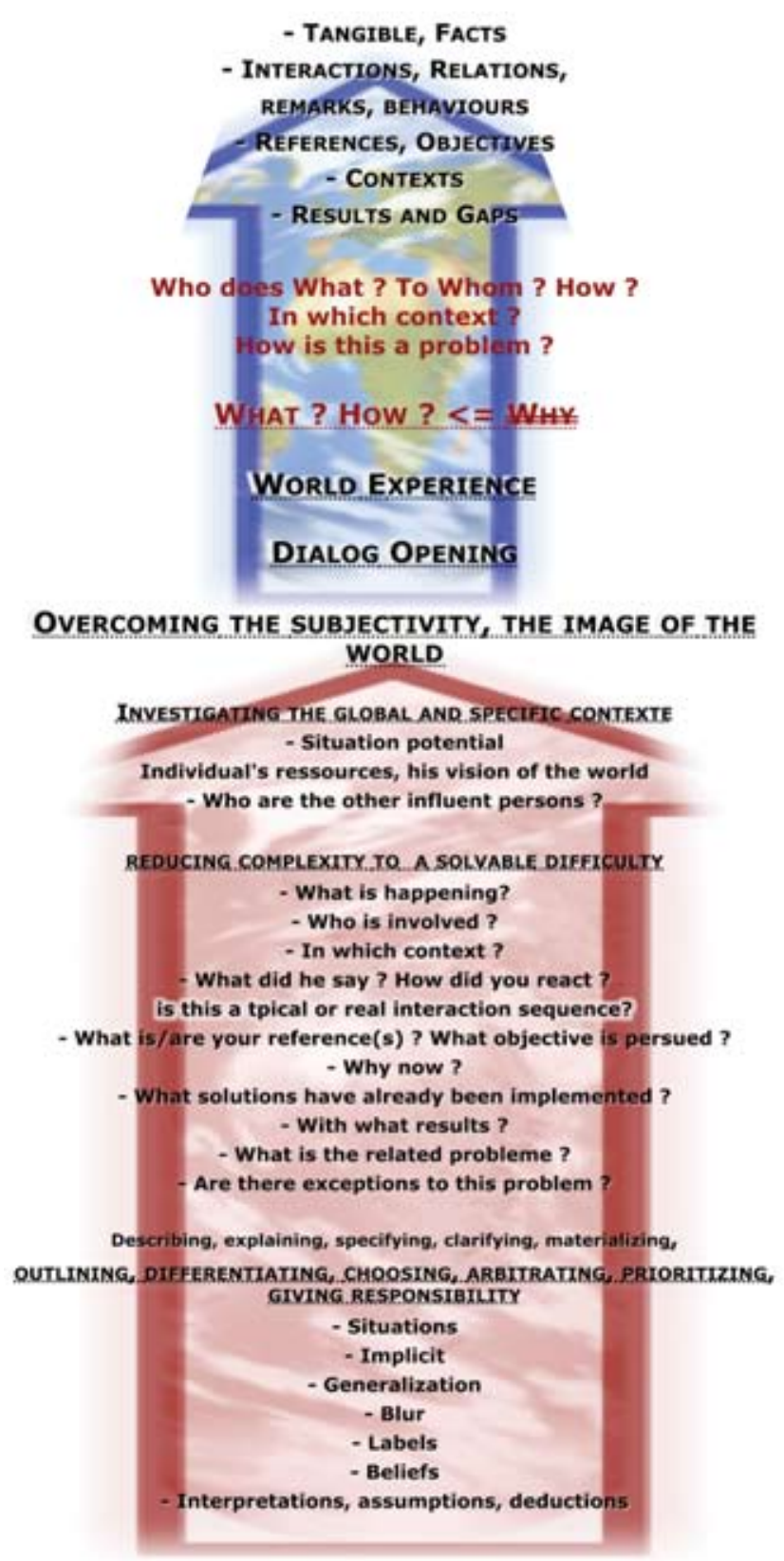

Figure 19: Questioning with perspicacity and precaution.
- a close vigilance (listening + observation) must be granted to the congruence of the languages used by the interlocutor and to their consistence (paradoxes);

o the emotional states arise and fill the communication.

- The communication in change relies on the interlocutor's communication, it uses it pour make constantly narrative and inductive rephrasings: paraphrases, analogies (as if ...), aphorisms, metaphors, anecdotes, interrogative formulations, illusory alternatives, humor, confusion, multiple negations, sprinkling, indirect suggestions, assumptions ... promote the emergence beyond the emotional obstacles.

- The most is made of all opportunities to open, enlarge and reframe at the same time, to influence perceptions, emotions, to create new logical links, etc, bring together the points of view ... relativize the difficulties, make the aptitudes and skills/competencies emerge.

- To be inductive, every request, injunction or "prescription" has to be slow, repetitive, focused on the interlocutor and punctuated with validations (series of YES sets).

- A dematerialized communication, even if it is interactive, is not an interaction, it is an "extrapersonal" communication. Since it suppresses an encounter, it skips part of the interpersonal languages, transforms the emotions, wanes the empathy capacities (see Figure 20).

\subsubsection{Universal Keys to Constructive Dialog}

- Pragmatic empathy

- Questioning and rephrasing, validations

- Strategy, perspicacity, content and form: relevant objective, caution in language, doubt, reframing, mobility, agility, flexibility

- A third (Middle) always exists, between the two poles of a contradiction on another reality level

\subsection{Letting Change Happen}




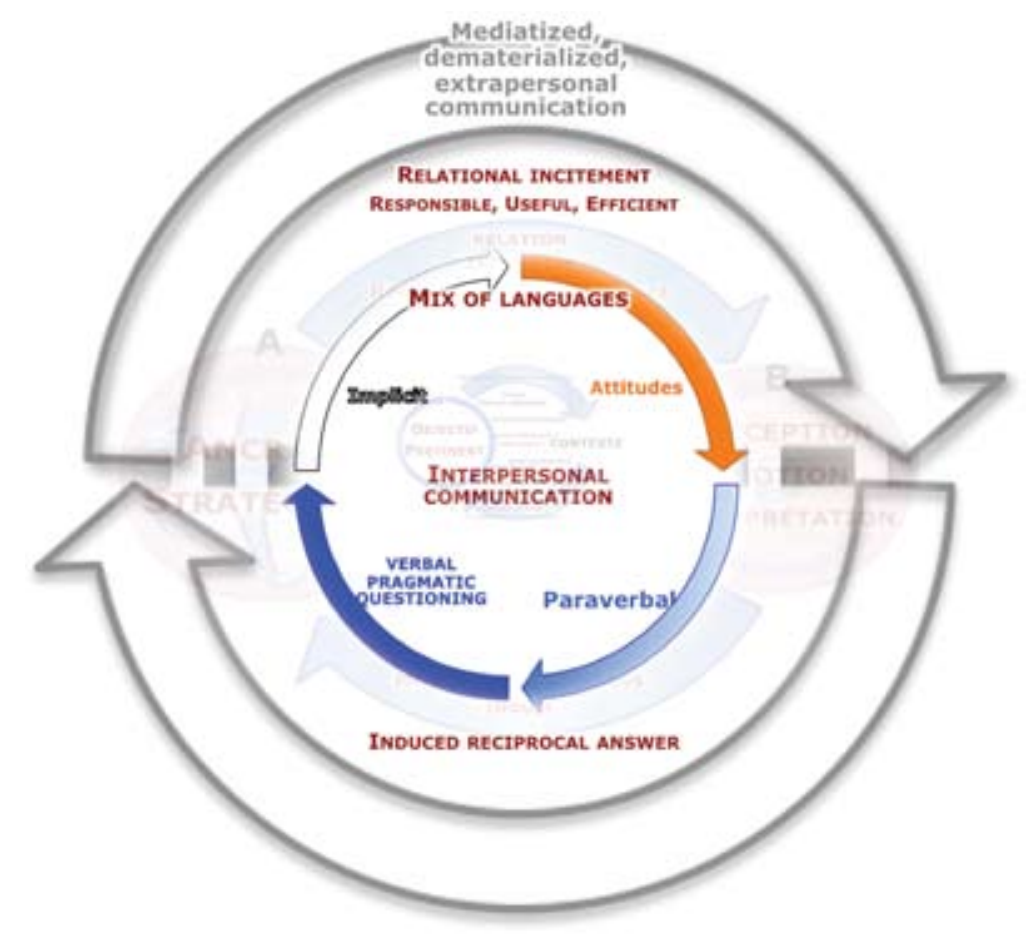

Figure 20: The inductive communication packages and serves relational strategy.

\subsubsection{From Auto-Regulation to the Choice of Change}

- Every relational movement is or consists of an adaptation at least, a change at the most.

- When the adaptation to the reference frame doesn't allow anymore to preserve an acceptable equilibrium on one reality level, synchronization to the context places the system if front of the choice to let a solution emerge on another reality level, in a new reference frame, therefore with another regulation and adaptation logic (see Figure 21).

- Change is an identity-related process because it comes under the free will of the individual, because it gives rise to renunciations sometimes experienced as denials, because it generates discomfort, most of the time.

- Asking a self-regulated system to change is a paradox! Change still remains to be obtained.

- Change requires a close, specific and identified relational support, and a communication that induces the movement.

\subsubsection{There is No Change Without Any Resistance Phase}

The Most Frequent Inappropriate Answers Given to Get a Change

- Persisting in implementing common sense solutions that don't work in the considered context

- Not aiming at a relevant objective, staying in one's illusions, utopias, "great ideas"

- Simplifying or denying a difficulty, thinking positive, going around without any strategy, procrastinating

- Analyzing, becoming aware, pondering, asking questions that have no answers, and not acting

- Denying the interlocutor's position and his vision of the world, "projecting oneself in his place" , trying to persuade, giving some advice Trying to impose one's ideas rather than implementing a Responsible, Useful and Efficient strategy

- Wasting one's efforts to solve problems in searching their causes

- Criticizing, blaming, disparaging, depreciating, belittling, making a person lose face 


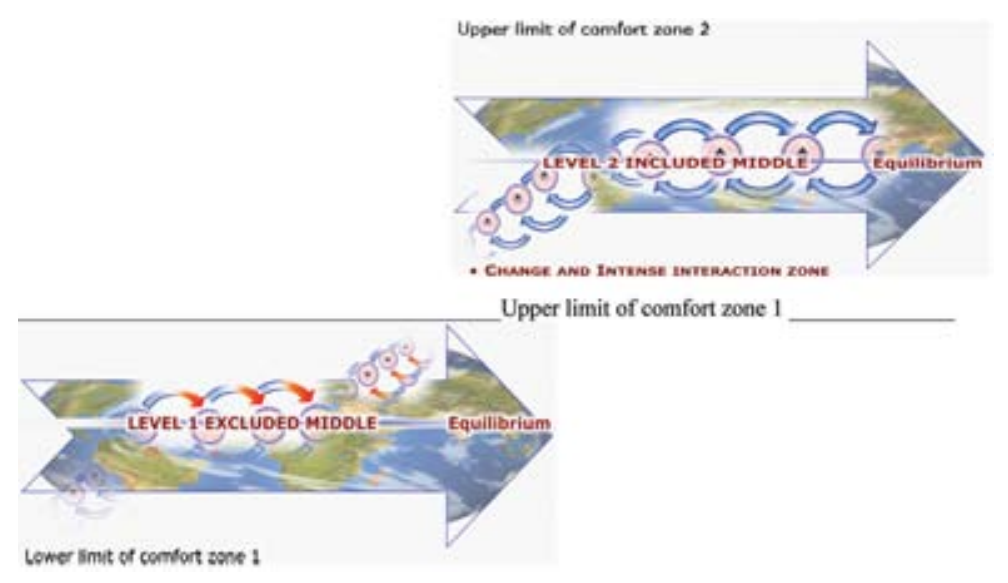

Figure 21: Change, is a change of reality level.

- ASKING FOR A CHANGE! Trying to control what is a matter of free will and of spontaneous behavior: trying to dominate the interlocutor's emotions, or what is a strong question of identity.

\subsubsection{A Protocol to Go Beyond the Resistance or Blocking Phases}

\subsubsection{Have All Dispositions of Precaution and Experience That Are Known to be of Common Sense Been Implemented?}

Listing all actions that have been implemented,

- Are the aimed at objectives relevant?

- Has the team been synchronized in project mode (risk review), upstream and downstream with the other entities of the organization?

- Has a specific mode of regulation been adopted?

- Have inductive relation et communication been deployed (relational empathetic anchoring, pragmatic questioning, inductive communication and rephrasings)?

- Have the resources coming from previous experiences and/or possible exceptions to the problem been exploited?

- Has the potential of the context been used opportunely? (See Figure 22).

\section{CHANGE}

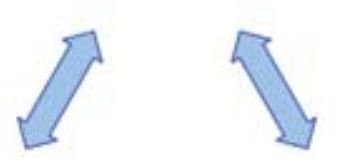

SMOOTH

RESISTANCES

Figure 22: There is no change without any resistance phase.

\subsubsection{Going Beyond a Resistance or Blocking Phase: When Common Sense Doesn't Go in the Right Sense, One Must Take the Other Way Round}

A chronic problem is a difficulty that is dealt with inappropriately and repeatedly relatively to a given context: this initial paradox is a contextual logic error that we are going to fix using a paradoxical action.

$\Rightarrow$ A. IDENTIFYING THE PROBLEM THAT HAS TO BE OVERTAKEN

- What is happening (Who - Does what - To whom)?

- For whom is this a problem?

- How is this a problem in this context?

$\Rightarrow$ B. DESCRIBING THE INAPPROPRIATE AND

REPEATED ANSWER THAT HAS ENCOUR- 


\section{AGED, CREATED AND MADE THE PROBLEM GO WORSE UNTIL NOW?}

$\Rightarrow \mathrm{C}^{* *}$. ADOPTING A STRATEGY THAT CONSTITUTES AN OPPOSITE INCITEMENT AT $-180^{\circ}$ - FROM THE ONE DESCRIBED PREVIOUSLY (or at least radically different)?

= USING THE PROBLEM, ACTUALIZING THE PROBLEM

- Aiming at an objective of change that is relevant and minimal.

$\Rightarrow$ D. TAKING A STRATEGIC REGULATING ACTION THAT WILL BLOCK THE PREVIOUS SOLUTIONS AND cause the emotion of change.

- Consolidating: considering a relapse, slowing down ...

$* * \Rightarrow$ C. USING THE PROBLEM, ACTUALIZING THE PROBLEM

The initial solution E implemented and actualized $\mathrm{A}(\mathrm{E})$ to solve the problem potentializes the resistance $=\mathrm{P}($ non $(\mathrm{E}))$ up to a blocking point.

Actualizing the potentialized resistance, the tension gives up and frees the Included Middle on another reality level.

In other words, using resistance according to modalities appropriate to the context, one uses the need for contradiction that values free will, and one changes the reality level, converting a problem into an opportunity for both parties.

\section{Using the Universal Keys to Constructive Dialog in Any Occurrences of Complexity}

- Pragmatic empathy

- Questioning and rephrasing, validations

- Strategy, perspicacity, content and form: caution in language, doubt, reframing, mobility, agility, flexibility

- A third (Middle) always exists, between the two poles of a contradiction on another reality level

\section{Nine Occurrences of Complexity and Relational Strategy to Be Implemented}

From occurrence of complexity, to its expression in any situation... the relational strategy, the means and resources to be implemented.

\subsection{Multiple}

\subsubsection{Expression}

- Person, character, situations, role plays, the individual is contextual, plural, different according to the various occurrences of his life

- The individual doesn't see himself acting: he dreams of himself the way he would like to be seen, he deludes and avoids himself

- An emotion can always hide another

- A point of view can always hide another

- An illusion can always hide another

- Multicausality, multifinality, variableness are the ingredients of the infinite combinatorics of the living

- Any context is the result of an infinite number of factors

- There cannot be two identical situations

\subsubsection{Relational Strategy}

- Being curious, perceptive, AND careful

- Sorting, eliminating, prioritizing, dividing: CHOOSING

- Practicing flexibility, mobility of the relational positions, agility on several reality levels, as a creative resource for reframing and for seeking a conciliatory solution

\section{Occurrences of Complexity and Relational Strategy}


- The transpositions "other things being equal" are inappropirate to a complex environment, since no situation never occurs identically

- Moving from the "WHY?" to the "HOW TO DO?": seeking THE cause can never solve a complex problem, since many causes gave rise to it; seeking the cause is endless, constantly renewed by the ever changing way the present is looked at

- Considering several solutions

\subsection{Several Reality Levels}

\subsubsection{Expression}

- A reality level is "a set of systems invariant under the action of a number of general laws". From a reality level to another, "there is a breaking of the laws and a breaking of the fundamental concepts" (Cf Basarab Nicolescu). For instance, in the professional relationship area:

o valuing the doubt as a resource / wanting to be right despite all opposition;

o trying to be useful and efficient / seeking objectivity, neutrality, truth;

- Trying to be useful and efficient / seeking objectivity, neutrality, truth, is a change in the reality level referring to new logical references. A change in organization is not a change of reality level.

\subsubsection{Relational Strategy}

- Practicing the relational agility, learning how to detect the reality levels, and how to move from one to another in order to open the sphere of possibilities, at every step of the dialog.

\section{Sample Founding Changes in the Reality Level $\Rightarrow$}

- shaping the strategic relationship / relying on the uncertainties of the contextual variations;

- making complementary what is contradictory / fighting against, conflicting, creating dilemmas;

- valuing the doubt as a resource / wanting to be right despite all opposition;
- dealing with the vagueness, the uncertainty and the unpredictable / acting only when there is no doubt;

- trying to be useful and efficient / seeking objectivity, neutrality, truth;

- choosing one's responsibility / being subject and executing;

- using gaps as a support for constant adaptation / pointing mistakes and sanctioning them;

- being future- and solution-oriented / seeking the causes;

- aiming at minimal relevant objectives / aiming at excellence at all costs;

- adopting the efficient relational-action strategy in order to change a behavior / figuring out the "why" of a behavior;

- combining reflection and action / becoming aware without taking action;

- replaying an unsatisfactory interaction / what is done is done.

\subsection{Contradiction}

\subsubsection{Expression}

- Each element constitutes one of the two poles of a contradiction

- Variety, difference, gap are inherent to complexity

- The universe is governed by the dynamics of contradiction: "What is not alike contrasts, what contrasts prompts the other part reciprocally" (Cf François Jullien)

- Subject and Object make up the supreme couple of contradictories

\subsubsection{Relational Strategy}

- An accepted and legitimate difference is a recognition that opens the dialog: dealing with, instead of fighting against, seeking the interlocutor's point of view

- The antagonism of the two poles of a contradiction leads to the doubt, to a maximum tension, from which can emerge, on another reality level, the conciliatory choice, in favor of continuity 
- Moving from "OR" one or the other, to "AND", together, at the same time, on another reality level, is like moving from $2 \mathrm{D}$ to $3 \mathrm{D}$

- Changing the reality level changes the logic: moving from a reality level that makes from an error a failure, to one that makes from differences and gaps contextual information that prompts to adaptation and progress.

- The period of change in the reality level requires a relationship that is especially attentive and an intense inductive communication

- The relational strategy leads to take the initiative of a conciliatory action

\subsection{Fate, Unpredictable, Impermanence}

\subsubsection{Expression}

- Like every complex system, the human is a black box: contextual, changing, unpredictable, etc.

- The sensitivity, emotional and affective potential of the human, his memorizing, association, reflection abilities are additionnal complexity factors

- An encounter is an emotional confrontation that can trigger an ego reaction radiating an unsuspected amount of energy

- The complexity of the interlocutor is a mystery that is experienced very emotionally, since it is unpredictable and singular, therefore risky and potentially carrying the imaginary anxiety of the worst ... (opposition, disagreement, blame, highlighting errors, weaknesses, or personal traits which are carefully, sometimes unintentionally, avoided)

\subsubsection{Relational Strategy}

- Practicing the relationship like a risky activity:

- escaping assertion

- making assumptions and bets, acting "as if"

○ combining perspicacity, caution and precautions

$\circ$ progressing with the detected gaps, completing using constant checking, adaptation and regulation
- Confronting any intellectual construction to what is tangible: action, implementation, experience make gaps emerge

- Future is prepared in the present, being ready for anything, even for a confrontation to what is unpredictable: agility, adaptability, flexibility have to be practiced and looked after

- If one never knows what a situation will require, one knows what should not be done anymore and how not to do it anymore

- Detecting the relevant information, what is potential, latent, using probabilities

- Using risk as a solidarity factor

- Using emotions and affectivity rather than seeking to control them

- Giving up trying to control what is uncontrollable, crying for the moon, radically banishing the questions that have no answers

\subsection{Non-Normativity}

\subsubsection{Expression}

- Complexity is non-standard: too many norms destroy The Norm

- One cannot live without interpreting

- Every individual interprets the facts his own way and creates his own image of the world

- The meaning of things belongs to nobody, and to everybody

- Reality, truth, neutrality and objectivity are "points of view"

- Everyone is right from his point of view, and everyone has good reasons to adopt a point of view

- Every point of view is identity-related: fighting against is like denying a person's existence

- The individuals interact from their interpretation of the world

- The human doesn't see himself acting, he dreams of himself the way he would like to be seen, he deludes and avoids himself 


\subsubsection{Relational Strategy}

- Without any opposable absolute norms, the initial co-creation consists, in every context, in the adoption of third, explicit and shared references/norms (Aim/project/objectives)

- The objective is third, mediator and catalyst in every relationship

- Choosing the Responsible, the Useful and the Efficient instead of truth, objectivity and neutrality

- Every Responsible, Useful and Efficient action is strategic in relation to the reference that is adopted in a given context

- Being accountable for the choice of one's representations and points of view

- Relating every position and every responsibility to the target reference

- Agreeing, seeking the interlocutor's point of view, systematically assigning to him the meaning of things, is the basis of a constructive exchange

- Aligning the dialog on the interlocutor's answers

- Aim, project, relevant objective fit together and divide themselves

- The relevant, explicit and shared objective is central to the effectiveness

- Aiming at a minimum objective is part of an improvement process

- Every reference has to be adapted and synchronized with the evolution of the context

- Generalities, great ideas, values exist only in their relation to the context

\subsection{Interdependence}

\subsubsection{Expression}

- Exchanging is vital: The human is essentially dependent, relational, systemic

- Information makes relationship

- There is no information without answer: they jointly and reciprocally make up both movements of the interaction loop

- The sequence of interaction loops makes the relationship
- The individual is only through his relationships, he is contextual

- The smallest entity under study: the individual in relation to the context

- The relationship makes foreseeable what is unpredictable and limits at the same time

- Influence is unavoidable, inherent to the person and to the character he/she plays in a given context

- The relationship to the context is a resource: the individuals, the right moment, what is potential, latent, the renewal of things

- Information, communication and relation are totally interlinked: the communication packages and opens the relationship

- The relationship makes the system, and the system controls the relationship to maintain an acceptable equilibrium

- The complex, open, self-regulated systems are inevitably interacting with their environment

- Every element of a system is in relationship with a number of other elements within this same system

- Every individual is an element from many systems at the same time

- The cause-consequence relationship is of a "many-to-many" and contextual type: an event can have several causes, and one cause can produce several results

- The smallest change in a relationship between two elements has consequences on the whole system

- A complex, open, self-regulated system tends to maintain its acceptable level of equilibrium

- The grouping of individuals in a complex system, develops some singular features

\subsubsection{Relational Strategy}

- Piloting an organized complex system, requires a regulation process that uses the logic of complexity

- Relationship can be practiced and piloted just like other activities 
- Relationship exists only through encounter: dematerialization and the use of medias cannot be considered as full substitutes

- Relationship feeds on and spreads out in its opening to the variety, to the logic of complexity, to the use of the potential of the context

- The realization systematically associates reflection and action

- Adopting a training approach: experiencing, renewing, entering dynamic learnings

- Using the gaps, limits, constraints of the system, as resources

- Aiming at a minimal action to get an optimal change

- The communication has to be practiced with the relationship

- The communication packages and serves the relationship: the mix of the 4 languages

- The inductive communication relies on the interlocutor's communication, it even uses it

- Reframing and injunctions are influence tools

- Relationship and communication serve the strategic influence

- Moving from the "WHY?" to the "HOW TO DO?" Seeking THE cause can never solve a complex problem, since many causes gave rise to it; seeking the cause is endless, constantly renewed by the ever changing way the present looks at the past, varying depending the "geographic" point of vie

- Locating and describing the relational sequences is more useful for the implementation of a solution than seeking the roots of a problem

- The transposition "other things being equal" is impossible

\subsection{Circularity, Alternation, Constant Renewal}

\subsubsection{Expression}

- An information and the answer to it follow different thought progressions: the interaction forms a loop

- The sequence of interaction loops makes the relationship
- In the interaction loops sequence, the poles of a contradiction overlap, mix up, change roles and are superimposed beyond a certain stage: Subject/Object; Beginning/End; Causes/consequences relative positions, are matters of opinion about the relationship in a given context

- A result is achieved through future-oriented iteration, adaptation, renewal, and synchronization

- The progress lies in the way one makes use of gaps

\subsubsection{Relational Strategy}

- Circularity is to the relationship and to communication, to the course of the events what the wheel is to mechanics and to moving: speed, reduction ratio, conversion, crossing of obstacles, change in the reality level, renewal, continuity

- The dynamics of permanent adaptation and regulation induces the calling into question, the risk taking.

- The progression through iteration loops combines itself to the progression towards the future: the orientation towards the seeking of a solution, carries innovation, experimentation, evolution and change

- The superimposition of the opposites in the sequence and progression of the interaction loops opens the space for representations and choice opportunities: information-answer, beginningend, initiator-follower, responsible-endured, can be an endless debate, or the choice of a representation in a given context, etc.

- The choice of responsibility is a question of position in relation to the context and to the adopted reference: changing the rules of the game

- The superimposition of the opposites in the sequence and progression of the interaction loops opens the space for paradoxical intervention: preliminary paradox / counter-paradox

- Choosing to take on a responsibility brings credibility and influence

- Everything can always be played again, more or less: as long as the end of a relational sequence has not been pronounced, one can always go 
back over an interaction that doesn't seem satisfactory

- The action's references obey to the same dynamics of regulation and adaptation

\subsection{Reciprocity}

\subsubsection{Expression}

- One cannot live without communicating: there is no information without answer

- One cannot live without adapting: dependence implies adaptation

- One cannot live without influencing: influence is inherent to the person and to the characters he/she plays

- The information and the answer are the two indissociable and reciprocal movements in an interaction

- Information and answer carry the image of the world of each of the interlocutors

- The line that divides responsibilities and influence appears between the information and the answer

- The incitement contained in the information creates the interpretation and the answer that follows

- The meaning of things belongs to the interlocutor

- The choice of the level and nature of the responsibility is a relative position-taking that influences its opposite

\subsubsection{Relational Strategy}

- Every interaction is an exchange in which both parties are respectively fully responsible of one of the two movements The line that divides responsibilities and influence just waits for a move: the context, like the adopted reference, endlessly lay down and re-shuffle the cards of the reciprocal responsibilities

- Giving substance to the relationship encourages to a constructive reciprocity: the expression space belongs to the interlocutor

- Pragmatic empathy is practiced through the rephrasing to the interlocutor; it avoids projection
- In the interaction loop, the tone is given by the interlocutor's answer

- Being accountable for a part of the responsibility in the relationship encourages the reciprocal responsibility-taking

- The choice of the position in the relationship is contextual

\subsection{Change}

\subsubsection{Expression}

- Change is part of the progression

- From auto-regulation to the choice of change, changing the reality level, the logical level to come back to an acceptable equilibrium

- Change is a process of calling into question that triggers an emotional "release", or even more if it is accompanied by some renunciation; it then becomes an identity claim

- There is no change without any resistance or blocking phase

- Asking for a change is a paradox, the decision of changing is an expression of the free will of the individual and of what he/she can claim in terms of freedom

\subsubsection{Relational Strategy}

- The maximum tension, the conflict between the two poles of the contradiction is the expression of the right moment from which the Included Middle can emerge

- Every change requires the implementation of minimal precaution and experience measures

- Since change is a project, it must be piloted as a project

- Dealing with what is, instead of fighting against

- Calling for resistances and problems

- Converting the energy of resistance into the energy of action and realization

- The element that resists has to be placed in a situation of realization

- A paradox is resolved using another paradox that leads to a change in the reality level ; actualizing the potentialized resistance, the tension gives up and frees the Included Middle on 
another reality level. In other words, using resistance according to modalities appropriate to the context, one uses the need for contradiction that values free will, and one changes the reality level, converting a problem into an opportunity for both parties.

- Going beyond a resistance or blocking phase: when common sense doesn't go in the change direction, one must take the other way round: preliminary paradox /counter-paradox

- Change is a very emotional process that requires a specific support

- At first sight, the solution, the Included Middle do not exist, it only emerges from the questioning in the relationship, and through the interlocutor's voice

\section{Universal Keys to Constructive Dialog and Piloting References in the Professional Relationship}

\subsection{Universal Keys to Constructive Dialog}

- Pragmatic empathy

- Adoption of a shared, explicit, and relevant reference

- Strategy and action serving the targeted action reference

- Perspicacity and caution, content and form: language precautions, doubt, questioningrephrasing, reframing

- Mobility, agility, flexibility: reality level, relative position in the relationship

- Reflection-action indissociable tandem

- Using contradiction as a reactional projection basis towards the Included Middle

\subsection{Piloting References in the Professional Relationship}

\subsubsection{Responsibility is a Chosen Option Beyond What Is Imposed and Resists to Our Experiences}

$\Rightarrow$ Sample Founding Changes in the Reality

\section{Level}

- the constraints in life refer to several reality levels / linear conception;

- shaping the strategic relationship / relying on "determinism" and on the uncertainties of the contextual variations;

- making complementary what is contradictory / fighting against, conflicting, creating dilemmas;

- valuing the doubt as a resource / wanting to be right despite all opposition;

- dealing with the vagueness, the uncertainty and the unpredictable / acting only when there is no doubt;

- trying to be useful and efficient / seeking objectivity, neutrality, truth;

- choosing one's responsibility / being subject and executing;

- aiming at minimal relevant objectives / aiming at excellence at all costs;

- using gaps as a support for constant adaptation / pointing mistakes and sanctioning them;

- describing the facts, being future- and solutionoriented / seeking the causes;

- adopting the efficient relational strategy-action in order to change a behavior / figuring out the "why" of a behavior;

- combining reflection and action / becoming aware without taking action;

- "things change" an unsatisfactory interaction can be played again / what is done is done.

\subsubsection{The Responsible, Useful and Efficient Professional Relationship}

\section{$\Rightarrow$ Aiming at a Responsible Useful and Efficient Relationship}

- practicing pragmatic empathy, inducing useful and efficient reciprocity;

- focusing on the interlocutor, seeking his/her logic, aligning his/her answers in order to pilot the dialog;

- agreeing explicitly on action references that are relevant in the context, aiming at minimal objectives; 
- putting relational strategy in the service of the result, using the potential of the context;

- looking after one's communication: mix of languages, perceptive and careful questioning, and inductive rephrasing and communication;

- practicing flexibility, mobility and relational agility: chosen and assumed responsibility, relative position, reality level;

- adopting the iterative dynamics of constant adaptation and regulation;

- combining reflection and action.

\subsubsection{Every Relational Movement Is or Consists of an Adaptation at Least, if Not a Change}

\section{$\Rightarrow$ Inducing and Driving Change}

- asking for a change is a paradox, change is yet to be obtained;

- ensuring that all dispositions of precaution, experience and common sense have been implemented;

- the initial risk review is the founding act of every change;

- establishing a close, specific and identified support process;

- inductive relationship and communication lead to change: deconstructing, de-framing, reframing, provoking, and calming down;

- when common sense doesn't go in the right sense, one must take the other way round;

- awareness doesn't make change, action is needed.

\section{Bibliography}

1. Nicolescu, B., 2009. "Qu'est-ce que la réalité ?" Editions Liber.

2. Nicolescu, B., 2010. Interférences : Stéphane Lupasco, Gaston Bachelard, André Breton, Salvador Dali, Georges Mathieu, Benjamin Fondane, Eugène Ionesco. In "A la confluence de deux cultures Lupasco aujourd'hui," Sous la direction de Basarab Nicolescu Editions Oxus, 2010, November.
3. Morin, E., 2010. Lupasco et les pensées qui affrontent les contradictions. In "A la confluence de deux cultures Lupasco aujourd'hui," Sous la direction de Basarab Nicolescu, Editions Oxus, 2010, November.

4. Malherbe, J-F., 2010. Esquisse d'une histoire de l'éthique à l'aune du "Tiers inclus" In "A la confluence de deux cultures Lupasco aujourd'hui," Sous la direction de Basarab Nicolescu Editions Oxus 2010, November.

5. Revardel, J-L., 2010. Stéphane Lupasco et la translogique de l'affectivitÉ. In "A la confluence de deux cultures Lupasco aujourd'hui," Sous la direction de Basarab Nicolescu Editions Oxus, 2010, November.

6. Morin, E., 2005. Introduction à la pensée complexe. Editions du Seuil avril $1^{\text {ere }}$ édition 1990 chez ESF éditeur.

7. Watzlawick, P., Weakland, H. J.,1981.Travaux du MRI Palo Alto (1965-1974). "Sur l'interaction" Traduit de "The interactional view", W.W. Norton \&Company, Inc. Editions du Seuil.

8. Wittezaele, J-J., 2003. L'homme relationnel. COULEURPSY SEUIL Octobre 2003.

9. Kourilsky, F., 2008. Du désir au plaisir de changer, 1995. Dunod $4^{e}$ édition mars.

10. Yves Doutrelugne, Y., 2008. Thérapies brèves : principes et outils pratiques. Olivier Cottencin Elsevier Masson SAS $2^{e}$ édition.

11. Goleman, D., 2006. Cultiver l'intelligence émotionnelle. Traduction : Editions Robert Laffont, 2009.

12. François Jullien, F., 1996. Traité de l'efficacité. Editions Grasset et Fasquel, Le Livre de poche, 1996, $6^{e}$ édition avril, 2010.

13. François Jullien, F., 1993. Figures de l'immanence, Editions Grasset et Fasquel, Grasset.

14. François Jullien, F., 2006. Le détour et l'accès, SEUIL, août.

\section{About the Author}

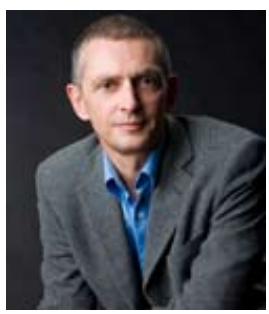


Luc Desbois is a Director of Studies at the Ecole de droitet de management (Paris Panthéon Assas University). Luc Desbois is graduated in economics, business administration and finance. As a former manager, he is a man of project with an entrepreneurial spirit. He has developed his expertise in the areas of management, human resources, change piloting, and corporate communication: founder and company manager in the automotive, press and publishing, and vocational training fields, executive manager in the banking sector, founder and director of Franoise Kourilsky associates since 2008. Trained to the systemic and constructivist approach by Franoise Kourilsky, the Gregory Bateson Institute (MRI, Liége), Teresa Garcia (MRI).

Copyright (c) 2012 by the author. This is an open access article distributed under the Creative Commons Attribution License (https://creativecommons.org/licenses/by/4.0/), which permits unrestricted use, distribution, and reproduction in any medium, provided the original work is properly cited. 